\title{
miR-200c is upregulated by oxidative stress and induces endothelial cell apoptosis and senescence via ZEB1 inhibition
}

\author{
A Magenta ${ }^{1}$, C Cencioni ${ }^{2}$, P Fasanaro ${ }^{3}$, G Zaccagnini ${ }^{1}$, S Greco ${ }^{3}$, G Sarra-Ferraris ${ }^{3}$, A Antonini ${ }^{1}$, F Martelli ${ }^{1}$ and MC Capogrossi ${ }^{\star *}$
}

We examined the effect of reactive oxygen species (ROS) on MicroRNAs (miRNAs) expression in endothelial cells in vitro, and in mouse skeletal muscle following acute hindlimb ischemia. Human umbilical vein endothelial cells (HUVEC) were exposed to $200 \mu \mathrm{M}$ hydrogen peroxide $\left(\mathrm{H}_{2} \mathrm{O}_{2}\right)$ for 8 to $24 \mathrm{~h}$; miRNAs profiling showed that miR-200c and the co-transcribed miR-141 increased more than eightfold. The other miR-200 gene family members were also induced, albeit to a lower level. Furthermore, miR-200c upregulation was not endothelium restricted, and occurred also on exposure to an oxidative stress-inducing drug: 1,3bis(2 chloroethyl)-1 nitrosourea (BCNU). miR-200c overexpression induced HUVEC growth arrest, apoptosis and senescence; these phenomena were also induced by $\mathrm{H}_{2} \mathrm{O}_{2}$ and were partially rescued by miR-200c inhibition. Moreover, miR-200c target ZEB1 messenger RNA and protein were downmodulated by $\mathrm{H}_{2} \mathrm{O}_{2}$ and by miR-200c overexpression. ZEB1 knockdown recapitulated miR-200c-induced responses, and expression of a ZEB1 allele non-targeted by miR-200c, prevented miR-200c phenotype. The mechanism of $\mathrm{H}_{2} \mathrm{O}_{2}$-mediated miR-200c upregulation involves p53 and retinoblastoma proteins. Acute hindlimb ischemia enhanced miR-200c in wild-type mice skeletal muscle, whereas in $\mathrm{p} 66^{\mathrm{ShcA}}-{ }_{-}-$mice, which display lower levels of oxidative stress after ischemia, upregulation of miR-200c was markedly inhibited. In conclusion, ROS induce miR-200c and other miR-200 family members; the ensuing downmodulation of ZEB1 has a key role in ROS-induced apoptosis and senescence.

Cell Death and Differentiation (2011) 18, 1628-1639; doi:10.1038/cdd.2011.42; published online 29 April 2011

Reactive oxygen species (ROS) play a causal role in a variety of cardiovascular diseases, including ischemia, ischemia/ reperfusion $(\mathrm{I} / \mathrm{R})$ injury, diabetic vasculopathy and atherosclerosis, and in aging. ${ }^{1-3} \mathrm{ROS}$, which include $\mathrm{H}_{2} \mathrm{O}_{2}$, superoxide anion and hydroxyl radicals have been demonstrated to inhibit cell growth and to induce cell death and senescence. ${ }^{1}$ MicroRNAs (miRNAs) are small non-coding RNAs, usually 21-23 nucleotides long, which regulate the stability and/or the translational efficiency of target messenger RNAs (mRNAs). ${ }^{4}$ They appear to be closely conserved across species and to them have been ascribed diverse functions, including regulation of proliferation, differentiation, senescence and death. ${ }^{5}$ The objective of the present work was to establish the effect of ROS on miRNAs expression, and to determine whether miRNAs modulate endothelial cells (EC) response to oxidative stress. In light of the important role that tumor suppressor proteins retinoblastoma $(\mathrm{pRb})$ and $\mathrm{p53}$ have in responses to ROS, we examined their contribution to miRNAs expression on oxidative stress exposure. The retinoblastoma family, which includes pRb, p130 and p107, is an integral part of the mechanism that regulates proliferation and senescence via phosphorylation-sensitive interactions, regulating either positively or negatively E2F transcription factors family. ${ }^{6} \mathrm{H}_{2} \mathrm{O}_{2}$ causes rapid $\mathrm{pRb}$ dephosphorylation by the activity of protein phosphatase $2 A^{7,8}$ and successively, by the increase of p53 protein, which in turns upregulates the CDK inhibitor p21 ${ }^{\text {Waf1/Cip1/Sdi1 }}$ (p21). ${ }^{7}$ The ROS effect on miRNAs expression was also evaluated in vivo, in a mouse model of hindlimb ischemia, both in wild-type (wt) and in p66 ${ }^{\text {ShcA }}$-null (p66 ${ }^{\text {ShcA-l- }}$ ) mice. The mammalian adaptor protein $\mathrm{p} 66^{\mathrm{ShcA}}$ regulates $\mathrm{ROS}$ metabolism and apoptosis. The cytoplasmic fraction of p66 $6^{\text {ShcA }}$ is phosphorylated in serine 36 residue in response to several stimuli, including UV and $\mathrm{H}_{2} \mathrm{O}_{2} \cdot{ }^{9}$ Moreover, a fraction of $\mathrm{p} 66^{\mathrm{ShcA}}$ is localized in the mitochondria and functions as a redox enzyme that generates ROS; ${ }^{10}$ accord-

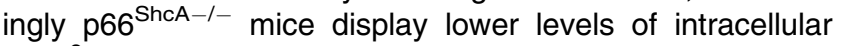
$\operatorname{ROS}^{9}$ and decreased oxidative stress levels and tissue damage following ischemia and I/R injury. ${ }^{2,3}$

In the present work, we show that miR-200 family was induced by oxidative stress in vitro. The most upregulated miRNA on $\mathrm{H}_{2} \mathrm{O}_{2}$-treatment in EC was miR-200c, and this induction was not restricted to the endothelium. Further, we linked the oxidative stress effects on EC proliferation, death and senescence to miR-200c upregulation and to the downmodulation of its target protein ZEB1. An increase in miR-200 family members was also observed in vivo, in mouse skeletal muscles following acute hindlimb ischemia, but this upregulation was strongly attenuated in $\mathrm{p} 66^{\text {ShcA-1- }}$ mice.

1'Laboratorio di Patologia Vascolare, Istituto Dermopatico dell'Immacolata - IRCCS, Via dei Monti di Creta 104, 00167 Roma, Italy; ${ }^{2}$ Centro Cardiologico Monzino - IRCCS, Laboratorio di Biologia Vascolare e Medicina Rigenerativa, Via Parea 4, 20138 Milano, Italy and ${ }^{3}$ Policlinico San Donato - IRCCS, Laboratorio di Cardiologia Molecolare, Via Morandi 30, San Donato Milanese, 20097 Milano, Italy

*Corresponding author: MC Capogrossi, Laboratorio di Patologia Vascolare, Istituto Dermopatico dell'Immacolata - IRCCS, Via dei Monti di Creta 104,00167 Roma, Italy. Tel: + 39066646 2429; Fax: + 39066646 2430; E-mail: capogrossi@ idi.it

Keywords: free radicals; endothelium; apoptosis; senescence; ischemia

Abbreviations: miRNA, microRNAs; ROS, reactive oxygen species; EC, endothelial cells

Received 04.6.10; revised 28.2.11; accepted 04.3.11; Edited by RA Knight; published online 29.4.11 


\section{Results}

Oxidative stress modulates miRNAs expression. Human umbilical vein EC (HUVEC) were exposed to $200 \mu \mathrm{M} \mathrm{H}_{2} \mathrm{O}_{2}$ for 8 and $24 \mathrm{~h}$ and miRNAs expression profile was determined; out of 250 miRNAs tested only 3 were modulated more than eightfold; miR-200c was upregulated, whereas miR-1 and miR-147 were downmodulated (see Supplementary Table S1 for complete data set). Validation by qPCR confirmed miR-200c increase and miR-1 decrease, whereas it failed to confirm miR-147 downmodulation. As miR-1 is muscle specific its $\mathrm{H}_{2} \mathrm{O}_{2}$ response was evaluated in C2C12 myoblasts. C2C12 exposed to $200 \mu \mathrm{M} \mathrm{H}_{2} \mathrm{O}_{2}$ showed miR-1 downmodulation both at 8 and $24 \mathrm{~h}$, and at the latest time point, miR-1 expression was $\sim 80 \%$ lower than control (not shown). miR-200c expression was examined in greater detail in HUVEC, the induction started at $2 \mathrm{~h}$ exposure to $\mathrm{H}_{2} \mathrm{O}_{2}$ and peak expression ( $\sim 30$-fold) was achieved after $16 \mathrm{~h}$ (Figure 1a). Moreover, miR-200c induction was dosedependent (Figure 1b).

Successively, it was evaluated whether miR-200c upregulation was induced by other interventions that cause red/ox imbalance. The alkylating agent 1,3-bis(2 chloroethyl)-1nitrosourea (BCNU) is a glutathione reductase inhibitor that blocks the conversion of oxidized to reduced glutathione. ${ }^{11,12}$ Incubation of HUVEC with BCNU for $2 \mathrm{~h}$ enhanced miR-200c and this phenomenon was inhibited by preincubation with free-radical scavenger $\mathrm{N}$-acetyl-L-cysteine (NAC; Figure 1c). ${ }^{12}$ Further, the $\mathrm{H}_{2} \mathrm{O}_{2}$-induced miR-200c upregulation was not limited to EC: it also occurred in human fibroblasts (Supplementary Figure $\mathrm{S} 1$ ) and in $\mathrm{C} 2 \mathrm{C} 12$, both in myoblasts and in myotubes (Figures $2 \mathrm{a}$ and $\mathrm{b}$ ).

miR-200 gene family is induced by $\mathrm{H}_{2} \mathrm{O}_{2}$. miR-200c belongs to miR-200 gene family with other four additional members. miR-200c and miR-141 are clustered on chromosome 12, whereas miR-200a, miR-200b and miR429 are clustered on chromosome 1. We established whether the entire miR-200 family was positively modulated by $\mathrm{H}_{2} \mathrm{O}_{2}$. We found that miR-141 was induced similarly to miR-200c (Figure 3 ). The other three clustered members, miR-200a, miR-200b and miR-429, were also induced by $\mathrm{H}_{2} \mathrm{O}_{2}$, albeit to a lower level (Figures $3 a$ and $b$ ).

It is worth noting that miR-200c is well expressed in HUVEC, whereas the other family miRNAs are barely detectable; therefore, miR-200c is likely the main effector of oxidative stress-induced biological responses.

miR-200c modulates EC proliferation, apoptosis and senescence. To establish the physiological relevance of miR-200c upregulation, HUVEC were infected with lentiviruses expressing either pre-miR-200c or a control sequence. We found that miR-200c overexpression significantly inhibited cell proliferation (Figure 4a); this result was supported by DNA synthesis decrease in HUVEC overexpressing miR-200c compared with control (Figure 4c). Moreover, serum deprivation caused a decrease in cell number and in bromodeoxyuridine (BrdU) incorporation (Figures $4 \mathrm{~b}$ and $\mathrm{c}$ ), which diminished even further on miR-200c overexpression (Figures $4 b$ and $c$ ).
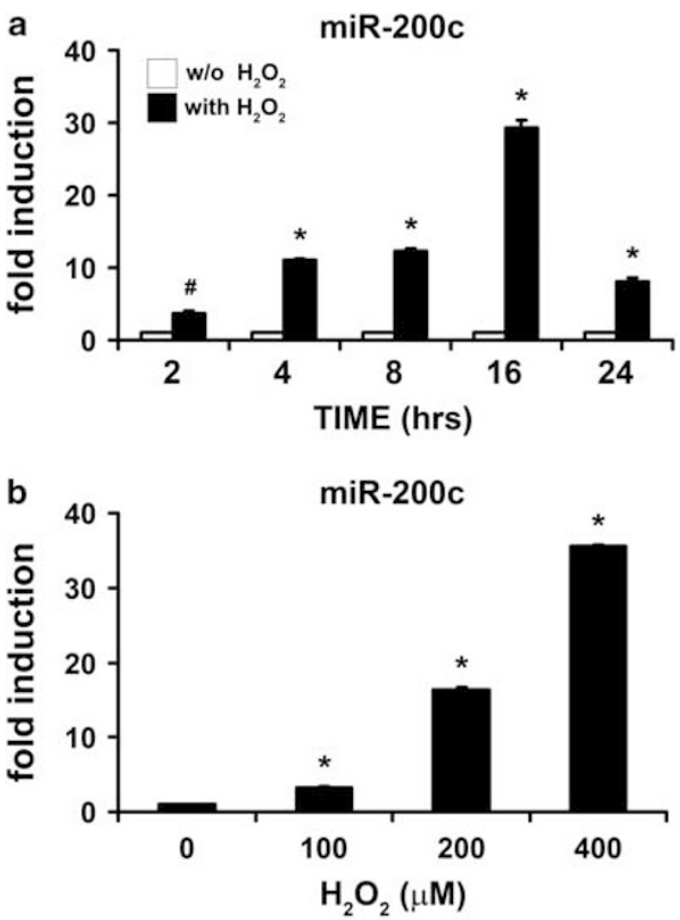

C

Figure 1 Oxidative stress induces miR-200c expression in HUVEC. (a) HUVEC were exposed to $200 \mu \mathrm{M} \mathrm{H}_{2} \mathrm{O}_{2}$ for 2-24h; miR-200c level is expressed as foldinduction versus untreated cells, at each time point. $\mathrm{H}_{2} \mathrm{O}_{2}$ enhanced miR-200c and peak expression was achieved after $16 \mathrm{~h}$ exposure to oxidative stress ( $n=4$ at each time point; ${ }^{\#} P<0.01 ;{ }^{*} P<0.001$ ). (b) HUVEC exposed to 100,200 or $400 \mu \mathrm{M} \mathrm{H}_{2} \mathrm{O}_{2}$ for $16 \mathrm{~h}$ exhibited a dose-dependent increase in miR-200c expression $(n=4$ at each time point; ${ }^{*} P<0.001$ ). (c) HUVEC were preincubated with $10 \mathrm{mM}$ NAC or sham treated for $30 \mathrm{~min}$, then cells were exposed to $0.25 \mathrm{mM} \mathrm{BCNU}$ for $2 \mathrm{~h}$. BCNU induced miR-200c upregulation, whereas pretreament with NAC followed by BCNU prevented miR-200c increase $\left(n=4 ;{ }^{\S} P<0.05\right)$

It was also examined miR-200c effect on cell death. In normal growth medium miR-200c overexpression enhanced apoptotic DNA fragmentation and the percentage of cells displaying subdiploid DNA content (Figures $5 a$ and $b$ ); these effects of miR-200c were amplified when cells were kept in starving conditions (Figures $5 \mathrm{a}$ and $\mathrm{b}$ ).

Finally, it was evaluated whether the inhibition of proliferation caused by miR-200c was also due to senescence. To this end, we tested the effect of miR-200c overexpression both on senescence-associated $\beta$-galactosidase (SA- $\beta$-gal) activity, a 

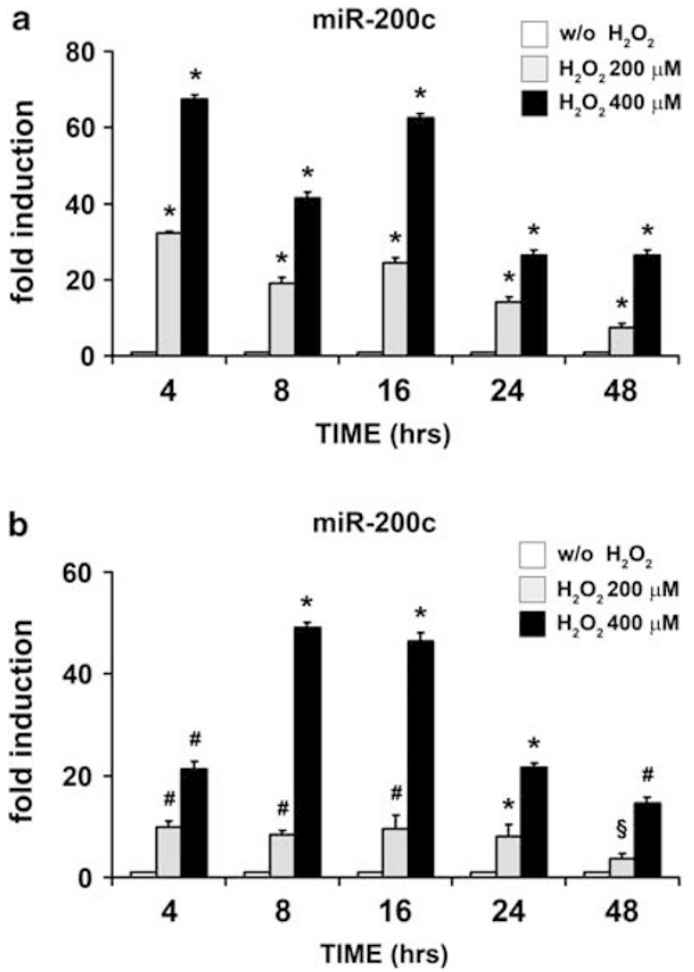

Figure $2 \mathrm{H}_{2} \mathrm{O}_{2}$ induces miR-200c expression in $\mathrm{C} 2 \mathrm{C} 12$ cells. (a) $\mathrm{C} 2 \mathrm{C} 12$ myoblasts cultured in growth medium were exposed either to 200 or $400 \mu \mathrm{M} \mathrm{H}_{2} \mathrm{O}_{2}$ for the indicated times. miR-200c was induced on $\mathrm{H}_{2} \mathrm{O}_{2}$ exposure and the increase was dose-dependent. miR-200 expression is indicated as fold-induction versus control ( $n=3$ at each time point; $\left.{ }^{*} P<0.001\right)$. (b) $\mathrm{C} 2 \mathrm{C} 12$ myotubes cultured in differentiation medium were exposed either to 200 or $400 \mu \mathrm{M} \mathrm{H}_{2} \mathrm{O}_{2}$ for the indicated times; oxidative stress induced miR-200c and the magnitude of the response was dose-dependent. miR-200c expression is indicated as fold-induction compared with untreated $\mathrm{C} 2 \mathrm{C} 12$ myotubes ( $n=3$ at each time point; ${ }^{\circledR} P<0.05$; ${ }^{\sharp} P<0.01$; $\left.{ }^{*} P<0.001\right)$ characteristic feature of senescence-related growth arrest, and on the expression of p21 protein, which increases in response to oxidative stress and has a major role in permanent growth arrest/senescence. ${ }^{13}$ In HUVEC transduced with miR-200c the percentage of SA- $\beta$-gal-positive cells was strongly increased compared with control (Figure 5c). Further, mir-200c overexpression markedly enhanced p21 (Figure 5d), whereas another senescenceassociated protein p16NK4A, did not increase (not shown).

We next evaluated whether miR-200c inhibition prevented oxidative stress-induced effects. To this end, HUVEC were transfected either with anti-miR-200c or with scramble oligonuleotides and thereafter exposed to $\mathrm{H}_{2} \mathrm{O}_{2}$. miR-200c inhibition caused, per se, a modest increase in $\mathrm{BrdU}$ incorporation and this upregulation was still present on $\mathrm{H}_{2} \mathrm{O}_{2}$ treatment (Figure 6a). Further, apoptotic DNA fragmentation diminished in anti-miR-200c transfected HUVEC and the decrease was present also in $\mathrm{H}_{2} \mathrm{O}_{2}$-treated cells (Figure $6 b$ ). Finally, cellular senescence was also inhibited by miR-200c blockade. In fact, upregulation of $\mathrm{p} 21$ by $\mathrm{H}_{2} \mathrm{O}_{2}$ was partially prevented in anti-miR-200c-expressing cells (Figure 6c).

Oxidative stress downmodulates ZEB1 protein via miR-200c. Since previous studies have established that miR-200 family members modulate ZEB1 and ZEB2 expression, ${ }^{14}$ we examined $\mathrm{H}_{2} \mathrm{O}_{2}$ effect on these targets. HUVEC were exposed to $200 \mu \mathrm{M} \mathrm{H}_{2} \mathrm{O}_{2}$ for 2 to $24 \mathrm{~h}$, ZEB1 protein downmodulation was apparent at $8 \mathrm{~h} \mathrm{H}_{2} \mathrm{O}_{2}$ exposure and lasted throughout the $24 \mathrm{~h}$ (Figure 7a). ZEB1 downmodulation was also observed in HUVEC exposed to $B C N U$ treatment and it was prevented by pretreatment with NAC (Figure 7b, see Supplementary Figure S2A for quantification). Further, it was found that $\mathrm{H}_{2} \mathrm{O}_{2}$ downmodulated ZEB1 mRNA, and the lowest expression

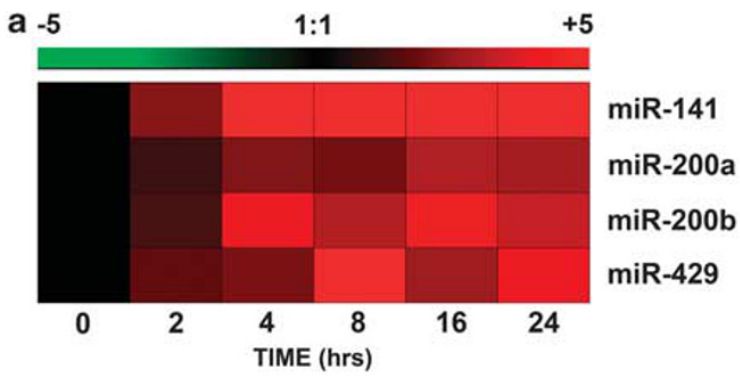

b

\begin{tabular}{|c|c|c|c|c|c|c|c|c|c|c|c|c|c|c|c|}
\hline & \multicolumn{3}{|c|}{$2 \mathrm{hrs}$} & \multicolumn{3}{|c|}{$4 \mathrm{hrs}$} & \multicolumn{3}{|c|}{8 hrs } & \multicolumn{3}{|c|}{$16 \mathrm{hrs}$} & \multicolumn{3}{|c|}{$24 \mathrm{hrs}$} \\
\hline & $\begin{array}{c}\text { fold } \\
\text { induction }\end{array}$ & SE & $\mathbf{p}$ & $\begin{array}{c}\text { fold } \\
\text { induction }\end{array}$ & SE & p & $\begin{array}{c}\text { fold } \\
\text { induction }\end{array}$ & SE & p & $\begin{array}{c}\text { fold } \\
\text { induction }\end{array}$ & SE & p & $\begin{array}{c}\text { fold } \\
\text { induction }\end{array}$ & SE & p \\
\hline $\operatorname{miR}-141$ & 2.29 & 0.29 & $\star \star$ & 8.84 & 0.71 & 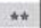 & 11.26 & 0.52 & $* * *$ & 23.28 & 0.49 & *t** & 7.58 & 0.47 & tim \\
\hline miR-200a & 1.14 & 0.53 & ns & 2.19 & 0.11 & \#*** & 1.99 & 0.75 & ns & 2.95 & 0.30 & $* *$ & 2.82 & 0.28 & ** \\
\hline miR-200b & 1.32 & 0.15 & $\star$ & 4.02 & 0.53 & * & 3.03 & 0.05 & $\star * * *$ & 4.36 & 0.14 & **** & 3.35 & 0.21 & $* * *$ \\
\hline $\operatorname{miR}-429$ & 1.69 & 1.86 & ns & 2.08 & 0.45 & * & 8.16 & 0.24 & 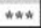 & 2.69 & 0.10 & 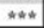 & 4.11 & 0.26 & ** \\
\hline
\end{tabular}

Figure $3 \quad \mathrm{H}_{2} \mathrm{O}_{2}$ induces miR-200 family expression in HUVEC. (a) Heat map represents miR-200 family miRNAs modulation in $\mathrm{HUVEC}$ exposed to $200 \mu \mathrm{M} \mathrm{H}_{2} \mathrm{O}_{2}$ for the indicated times. Modulations are expressed using a log2 scale $(-\Delta \Delta \mathrm{Ct})$. Green and red indicate down- and up-regulation, respectively. The experiment was performed four times with similar results. (b) Average results for the experiment depicted in (a), displayed using a linear scale. On $\mathrm{H}_{2} \mathrm{O}_{2}$ treatment miR-141 exhibited an induction comparable to that of miR-200c and achieved its peak level after $16 \mathrm{~h}$ exposure to oxidative stress. The other miRNAs were all induced by $\mathrm{H}_{2} \mathrm{O}_{2}$ but to a lower level, that is, $\sim 3-8-f_{0}$ ld increase. The expression level of each miRNA is indicated as fold-induction versus untreated cells $\left(n=4\right.$ at each time point; ${ }^{\star} P<0.05 ;{ }^{\star *} P<0.01 ;{ }^{* \star} P<0.001 ;$ non significant $=$ n.s.) 

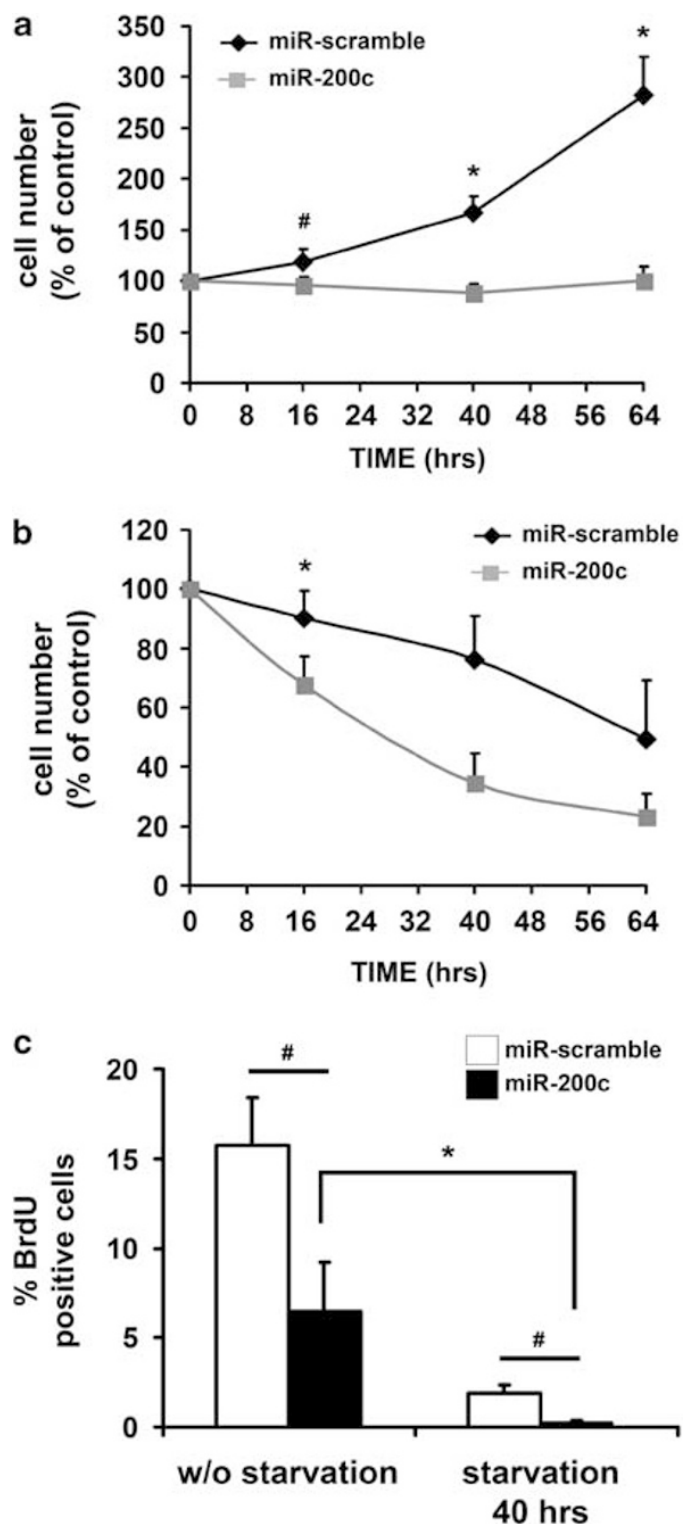

Figure 4 miR-200c inhibits EC proliferation and BrdU incorporation. HUVEC were infected either with a lentivirus encoding miR-200c or with a control virus. After $24 \mathrm{~h}$, cells were selected with puromycin and plated. (a) miR-200c overexpression inhibited cell proliferation compared with control; cells were counted at different time points ( $n=5$ at each time point; ${ }^{*} P<0.05 ;{ }^{*} P<0.001$ ). (b) HUVEC transduced with miR-200c or control virus were serum deprived for the indicated times. Cells were counted at different time points and both groups exhibited a progressive decrease in number, which was more marked in miR-200c overexpressing cells versus control $\left(n=5\right.$ at each time point; $\left.{ }^{*} P<0.05\right)$. (c) HUVEC transduced with miR-200c or control virus were serum deprived or kept under control conditions for $40 \mathrm{~h}$. Thereafter cells were pulse labelled with $\mathrm{BrdU}$ for $30 \mathrm{~min}$ before collecting, fixed and then stained with propidium iodide and an $\alpha$-BrdU antibody. miR-200c overexpression decreased the percentage of BrdU-positive cells and this effect was amplified in cells kept under starving conditions $\left(n=3\right.$; $\left.{ }^{\sharp} P<0.05 ;{ }^{*} P<0.01\right)$

level was achieved after $16 \mathrm{~h}$ exposure to $\mathrm{H}_{2} \mathrm{O}_{2}$ (Figure 7c); notably, ZEB1 mRNA was inversely related to miR-200c and miR-141 induction (compare Figures 1a-3 with Figure 7c). The $\mathrm{H}_{2} \mathrm{O}_{2}$ effect on ZEB2 protein could not be established because its level was undetectable in HUVEC. In contrast,
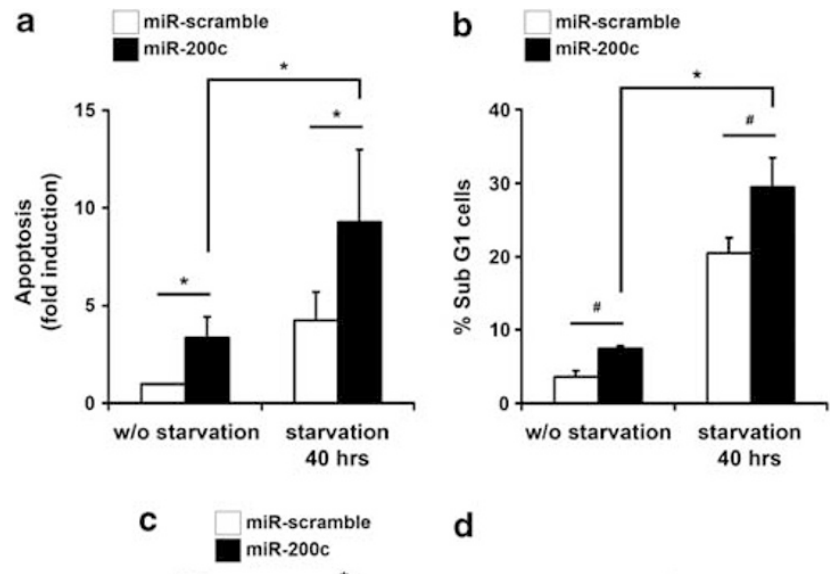

d
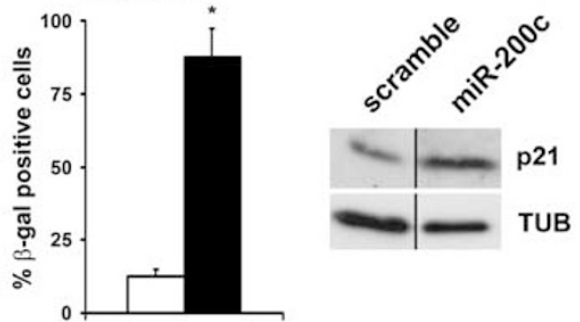

Figure 5 miR-200c induces EC apoptosis and senescence. The effect of miR$200 \mathrm{c}$ forced expression was evaluated in HUVEC infected with lentiviruses encoding either miR-200c or a scramble sequence (miR-scramble). After $24 \mathrm{~h}$ and puromycin selection, HUVEC were kept in control medium or serum deprived for additional $40 \mathrm{~h}$ before the final analyses. Apoptosis was determined by (a) fragmentation of cellular DNA $\left(n=3 ;{ }^{*} P<0.05\right)$ or (b) as the percentage of propidium iodide-stained cells displaying subdiploid DNA content by flow cytometry $\left(n=3 ;{ }^{\sharp} P<0.01 ;{ }^{*} P<0.001\right)$. Overexpression of miR-200c-induced apoptosis and this effect was enhanced in cells kept under starving conditions. (c) HUVEC transduced with miR-200c or control virus were fixed and stained for SA- $\beta$-gal. Overexpression of miR-200c induced a strong increase in SA- $\beta$-gal-positive cells compared with control $\left(n=3 ;{ }^{*} P<0.001\right)$. (d) HUVEC were transduced either with miR-200c or with control virus. After selection, cells were plated at the same confluence and collected after $8 \mathrm{~h}$. A representative western blot shows that miR$200 \mathrm{c}$ induced p21 protein. The experiment was performed three times with similar results. Tub indicates $\alpha$-tubulin

ZEB2 mRNA was expressed but the $\mathrm{H}_{2} \mathrm{O}_{2}$ effect was relatively minor, and a statistically significant difference from control was achieved only after $2 \mathrm{~h}$ treatment (Supplementary Figure S2B).

miR-200c-overexpressing HUVEC exhibited a 53\% decrease in ZEB1 mRNA (Figure 7d, left panel), whereas ZEB2 mRNA decrease was minor and not statistically significant (Supplementary Figure S2C). As expected, ZEB1 protein was downmodulated by miR-200c overexpression (Figure 7d, right panel).

ZEB1 knockdown modulates EC proliferation, apoptosis and senescence. Successively, we asked whether miR200c overexpression effects could be reproduced by ZEB1 depletion. To this end, HUVEC were infected with lentiviruses encoding either ZEB1-specific shRNA sequence or a control sequence. We found that ZEB1 knockdown markedly inhibited cell proliferation (Figure 8a) and induced cell death (Figure 8b). Finally, HUVEC depleted of ZEB1 showed an 

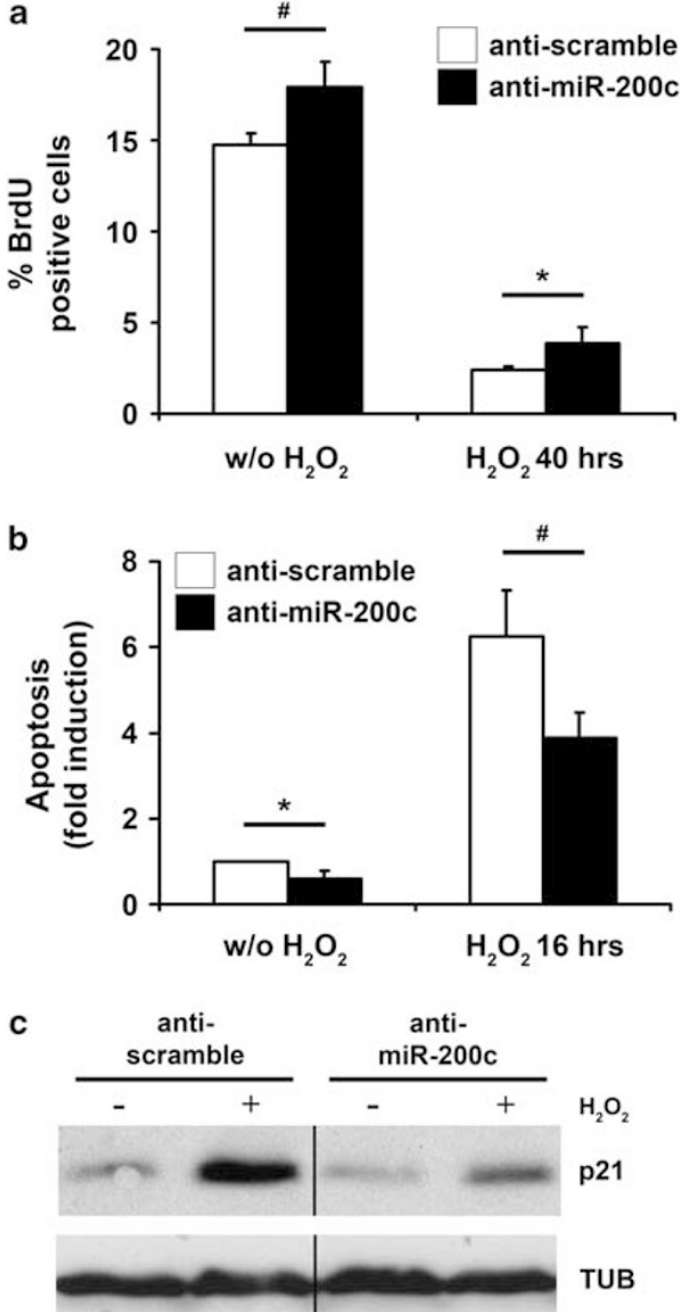

Figure 6 miR-200c inhibition partially rescues the effects induced by oxidative stress. (a) HUVEC were transfected either with scramble (anti-scr) or anti-miR-200c (anti-miR-200c) LNA-oligonucleotides. After $16 \mathrm{~h}$, cells were incubated with fresh medium for $8 \mathrm{~h}$ and then $200 \mu \mathrm{M} \mathrm{H}_{2} \mathrm{O}_{2}$ was added to the cells for additional $40 \mathrm{~h}$. Afterwards cells were pulse labelled with $\mathrm{BrdU}$ for $30 \mathrm{~min}$ before collecting, fixed and then stained with propidium iodide and a $\alpha$-BrdU antibody. Bar graph representing BrdU incorporation shows an increase in DNA synthesis in HUVEC transfected with anti-miR-200c compared with control, both in the absence and in the presence of oxidative stress $\left(n=3 ;{ }^{*} P<0.01 ;{ }^{\#} P<0.05\right)$. (b) HUVEC were transfected with anti-scramble or anti-200c LNA-oligonucleotides, $24 \mathrm{~h}$ later, cells were exposed to $200 \mu \mathrm{M} \mathrm{H}_{2} \mathrm{O}_{2}$ for additional $40 \mathrm{~h}$. Then apoptosis was measured by determining fragmentation of cellular DNA. Cells transfected with anti-miR-200c exhibited a decrease in apoptosis both in the absence and in the presence of oxidative stress $\left(n=5\right.$; ${ }^{*} P<0.01$; ${ }^{*} P<0.05$ ). (c) HUVEC were transfected either with anti-scramble or anti-200c LNA-oligonucleotides; $24 \mathrm{~h}$ later cells were exposed to $200 \mu \mathrm{M} \mathrm{H}_{2} \mathrm{O}_{2}$ for additional $16 \mathrm{~h}$. The immunoblot with anti-p21 shows that anti-miR-200c partially prevented p21 induction caused by $\mathrm{H}_{2} \mathrm{O}_{2}$. The experiment was performed three times with similar results. Tub, $\alpha$-tubulin

induction of senescence, displaying a higher percentage of SA- $\beta$-gal-positive cells (Figure 8c, left panel), and an increase of p21 protein (Figure 8c, right panel). Further, in ZEB1 knocked-down HUVEC p16INK4A did not increase (not shown).

These results are unlikely due to off-target RNA interference (RNAi) effects, as similar results were obtained
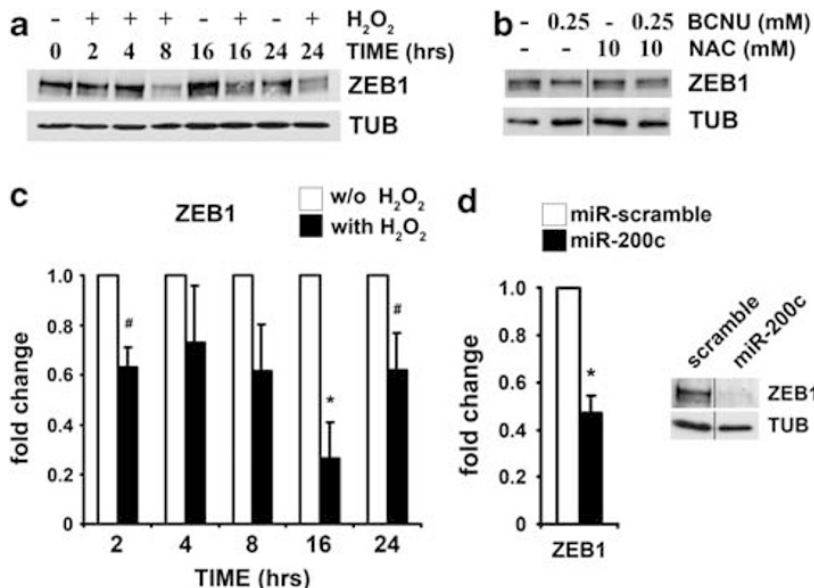

miR-scramble iR-200c

Figure 7 Oxidative stress downmodulates ZEB1. (a) HUVEC were treated with $200 \mu \mathrm{M} \mathrm{H}_{2} \mathrm{O}_{2}$ for 2-24h and ZEB-1 protein was evaluated by western blotting analysis. Oxidative stress decreased ZEB1; this effect was apparent after $8 \mathrm{~h}$ exposure to $\mathrm{H}_{2} \mathrm{O}_{2}$ and lasted throughout the $24 \mathrm{~h}$ time course of the study. This experiment was repeated four times with similar results. (b) HUVEC were either preincubated with $10 \mathrm{mM} \mathrm{NAC}$ or sham treated for 30 min before exposure to $0.25 \mathrm{mM} \mathrm{BCNU}$ for $2 \mathrm{~h}$. A representative western blot shows that BCNU downmodulated ZEB1 protein and this decrease was prevented by pretreatment with the oxidative stress scavenger NAC. This experiment was repeated three times with similar results. (c) HUVEC were treated with $200 \mu \mathrm{M} \mathrm{H}_{2} \mathrm{O}_{2}$ for 2-24h and ZEB1 mRNA was quantified by qPCR; ZEB1 lowest expression level versus control was achieved after $16 \mathrm{~h}$ exposure to oxidative stress ( $n=4$ at each time point; ${ }^{*} P<0.01 ;{ }^{\#} P<0.05$ ). (d) Left panel: HUVEC were infected with a lentiviral vector encoding either miR-200c or miR-scramble. After $24 \mathrm{~h}$, cells were selected with puromycin and ZEB1 mRNA was quantified by qPCR; miR-200c overexpression downmodulated ZEB1 mRNA $\left(n=3 ;{ }^{*} P<0.001\right)$. Right panel: HUVEC were transduced either with miR-200c or with control virus. After selection cells were plated at the same confluence and collected after $8 \mathrm{~h}$. A representative western blot shows that miR-200c overexpression downmodulated ZEB1. This experiment was performed four times with similar results. Tub indicates $\alpha$-tubulin $(n=4)$

with three other independent shRNA (ZEB1-a, ZEB1-b and ZEB1-c) that effectively repressed ZEB1 expression (Supplementary Figure S3).

ZEB1 downmodulation is required for miR-200cmediated effects. We investigated whether ZEB1 downmodulation was an integral part of miR-200c-induced phenotype. To this aim, miR-200c was overexpressed in HUVEC in the presence of a ZEB1 allele devoid of most 3 'UTR sequence (ZEB1 $\triangle$ ), and that therefore, cannot be targeted by miR-200 family miRNAs (Figure 9a). ZEB1 $\Delta$ and miR-200c were both expressed by lentiviruses. ZEB1 $\Delta$ and miR-200c simultaneous expression increased cell proliferation and markedly inhibited miR-200c-induced apoptosis (Figures $9 \mathrm{~b}$ and c). Finally, ZEB1 $\Delta$ and miR200c coexpression prevented miR-200c-dependent senescence (Figure 9d). It is important to underline that ZEB1 $\Delta$ expression had no effect per se.

Mechanism of miR-200c induction by $\mathrm{H}_{2} \mathrm{O}_{2}$. To establish whether the $\mathrm{H}_{2} \mathrm{O}_{2}$-mediated miR-200c upregulation was transcriptionally regulated, we analyzed the expression levels of miR-200c precursors in $\mathrm{H}_{2} \mathrm{O}_{2}$-treated HUVEC. 


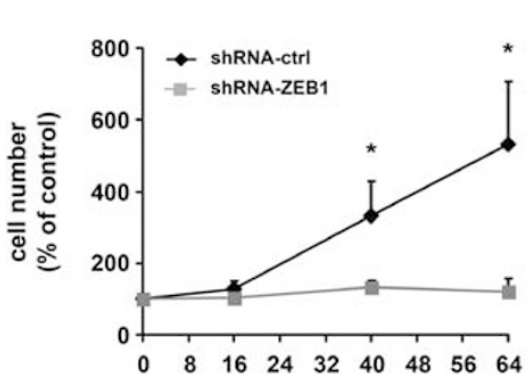

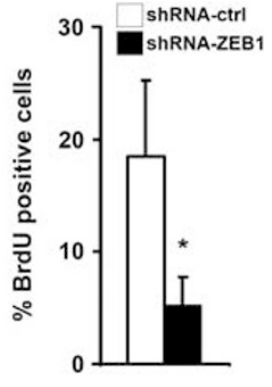

b
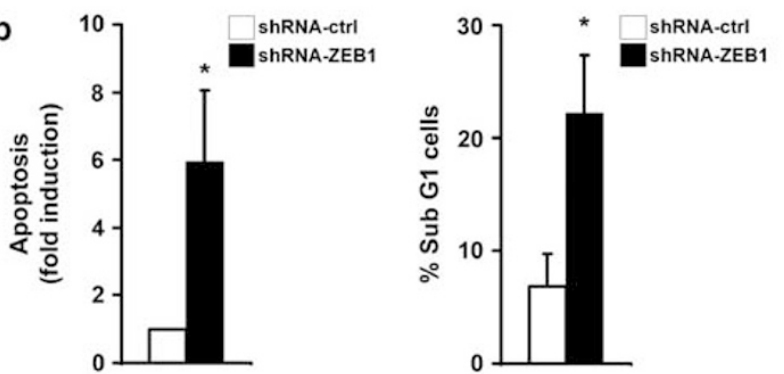

C
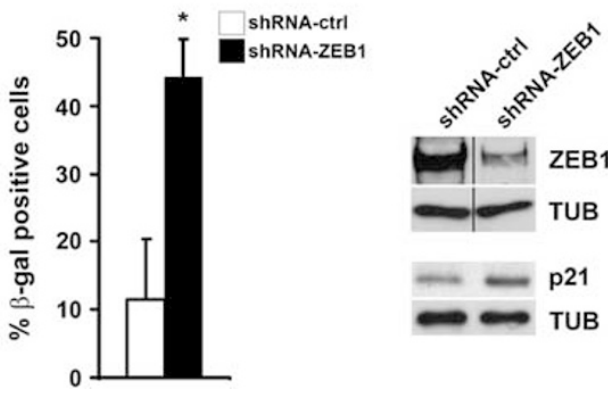

Figure 8 Functional effects of ZEB1 knockdown in EC. (a) Left panel: HUVEC were infected either with the lentivirus carrying ZEB1-specific shRNA or with the control virus. After $24 \mathrm{~h}$, cells were selected with puromycin and plated. ZEB1 knockdown inhibited cell proliferation compared with control $\left(n=3\right.$; $\left.{ }^{*} P<0.05\right)$. Right panel: HUVEC were transduced with shRNA-ZEB1 or with control virus. After selection, cells were plated and $40 \mathrm{~h}$ later were pulse labelled with BrdU for 30 min before collecting, fixed and then stained with propidium iodide and an $\alpha$-BrdU antibody. Bar graph representing BrdU incorporation showed a decrease of DNA synthesis in HUVEC knocked down for ZEB1 compared with control cells $(n=3$; $\left.{ }^{*} P<0.05\right)$. (b) HUVEC were transduced with shRNA-ZEB1 or with control virus. After selection, cells were plated and $40 \mathrm{~h}$ later apoptosis was measured. Left panel: ZEB1 depletion induced apoptosis as determined by fragmentation of cellular DNA $\left(n=3\right.$; $\left.{ }^{*} P<0.05\right)$. Right panel: ZEB1 depletion increased the number of cells in sub-G1 phase of the cell cycle as determined by the percentage of cells displaying subdiploid DNA content by flow cytometry $\left(n=3 ;{ }^{*} P<0.05\right)$. (c) Left panel: HUVEC transduced with shRNA-ZEB1 or with control virus were seeded and after $8 \mathrm{~h}$ were fixed and stained for SA- $\beta$-gal. ZEB1 knockdown enhanced the percentage of SA$\beta$-gal-positive cells compared with control $\left(n=3 ;{ }^{*} P<0.05\right)$. Right panel: representative western blot demonstrating a 70\% knockdown of ZEB1 expression in HUVEC infected with a lentivirus encoding a ZEB1-specific shRNA sequence compared with control virus-infected cells. HUVEC transduced with a ZEB1-specific shRNA show an upregulation of p21 compared with control. The same protein extracts were run on a $6 \%$ SDS polyacrylamide gel to detect ZEB1 and on a $12 \%$ to detect p21. This experiment was performed three times with similar results. Tub, $\alpha$-tubulin

miR-200c and miR-141 are co-transcribed in a common precursor (pri-miR-200c-141). We found that $\mathrm{H}_{2} \mathrm{O}_{2}$ treatment induced pri-miR-200c-141 expression. Interestingly, the time course of pri-miR-200c-141 induction was similar to that of the mature species, starting at $2 \mathrm{~h}$ and peaking at $6 \mathrm{~h}$ (compare Figure 10a, Figure 1a and Figure 3). Unfortunately, we were unable to detect pre-miR-200c in our experimental conditions. We also analyzed the response of miR-200c and miR-141 common promoter to $\mathrm{H}_{2} \mathrm{O}_{2}$. The transfection procedure is highly toxic to HUVEC, therefore this experiment was performed in $\mathrm{C} 2 \mathrm{C} 12$ myoblasts. miR-200c promoter was induced almost twofold by $\mathrm{H}_{2} \mathrm{O}_{2}$ (Supplementary Figure S4A). Similarily, in the adopted experimental conditions, miR-200c RNA displayed a similar level of induction (Supplementary Figure S4B). Furthermore, miR-200c promoter mutated in both ZEB1 conserved binding sites ( $Z 1 / 2$ boxes), exhibited a higher basal expression level compared with wt (Supplementary Figure S4A), confirming the ZEB1/miR-200c gene inhibitory-loop. ${ }^{14}$ In keeping with this result, $\mathrm{H}_{2} \mathrm{O}_{2}$ induced no significant increase of $\mathrm{Z1/Z2-}$ mutated promoter activity, suggesting that $\mathrm{H}_{2} \mathrm{O}_{2}$ induction of the promoter was largely mediated by ZEB1 downregulation (Supplementary Figure S4A). Finally, to further demonstrate the existence of ZEB1/miR-200 double-negative feedback loop in HUVEC, we analyzed the expression levels of miR-200 family in ZEB1 knocked-down cells. We found that the inhibition of ZEB1 via RNAi in HUVEC, induced an upregulation of all family members: with the highest levels achieved by miR-200c and miR-141 (Supplementary Figure S4C).

Successively, we investigated whether $\mathrm{pRb}$, which regulates cell proliferation and senescence, was involved in $\mathrm{H}_{2} \mathrm{O}_{2}$ mediated miR-200c upregulation. miR-200c overexpression induced, as expected, $\mathrm{pRb}$ dephosphorylation at a level comparable to $16 \mathrm{~h} \mathrm{H}_{2} \mathrm{O}_{2}$ exposure (Figure 10b). pRb phosphorylation was analyzed by western blotting, both using a $\mathrm{pRb}$ phospho-specific antibody $\mathrm{y}^{7,8}$ and measuring the abundance of the slower-migrating, hypophosphorylated form of $\mathrm{pRb}$. Moreover, HUVEC transfected either with anti-miR$200 \mathrm{c}$ or with scramble oligonuleotides, were exposed to $\mathrm{H}_{2} \mathrm{O}_{2}$ for 16h (Figure 10c). miR-200c inhibition caused, per se, a slight increase of pRb phosphorylation; on $\mathrm{H}_{2} \mathrm{O}_{2}$ exposure $\mathrm{pRb}$ dephosphorylation in anti-miR-200c transfected cells was significantly lower than in control cells (Figure 10c). These data are in agreement with our previous results showing enhanced BrdU incorporation in anti-miR-200c transfected cells compared with control (Figure 6a). As ZEB1 transcription has been demonstrated to be controlled by $\mathrm{pRb}$ family/E2F cell cycle pathway, ${ }^{15}$ we investigated whether $\mathrm{pRb}$ was implicated in miR-200c upregulation. To this aim we took advantage of Mouse embryonic fibroblasts (MEFs) carrying conditional $R b$ alleles ( $\left.R b^{\text {LoxP/LoxP }} \mathrm{MEFs}\right)$ in which two LoxP sites are inserted into the introns surrounding exon 19 of the $R b$ gene. $R b^{\text {LoxP/LoxP }}$ MEFs infected with an adenovirus expressing the Cre recombinase (AdCre) that excises exon 19 were exploited to generate cells with truncated $\mathrm{pRb}\left(R b^{-/-} \mathrm{MEFs}\right) ; R b^{\text {LoxP/LoxP }} \mathrm{MEFs}$ infected with an adenovirus that did not express the Cre transgene were used as control $\left(R b^{\text {LoxP/LOXP }}\right)$. On $\mathrm{H}_{2} \mathrm{O}_{2}$ treatment miR-200c increase in $R b^{-1-}$ MEFs was markedly lower than in $R b^{\text {LoxP/LoxP }}$ MEFs, indicating an active role of $\mathrm{pRb}$ in miR-200c upregulation by $\mathrm{H}_{2} \mathrm{O}_{2}$ (Figure 10d).

Given the importance of $\mathrm{p} 53$ in $\mathrm{EC}$ response to oxidative stress, we evaluated whether p53 also was implicated in 
a

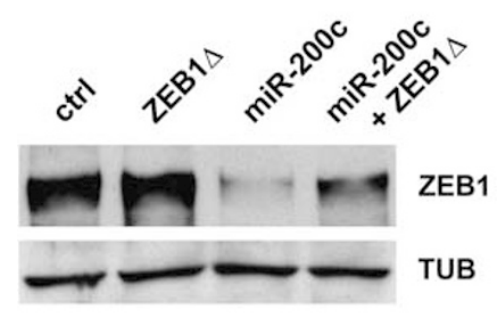

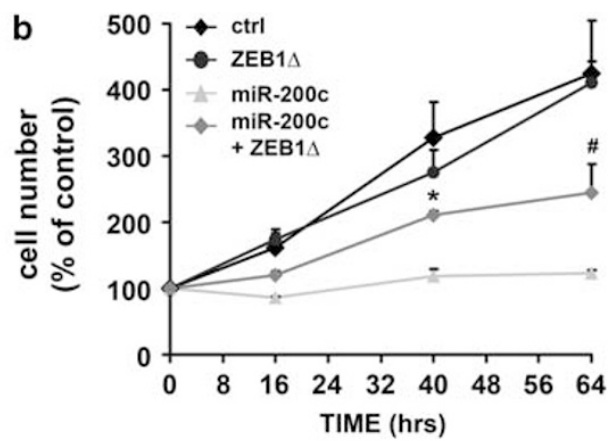

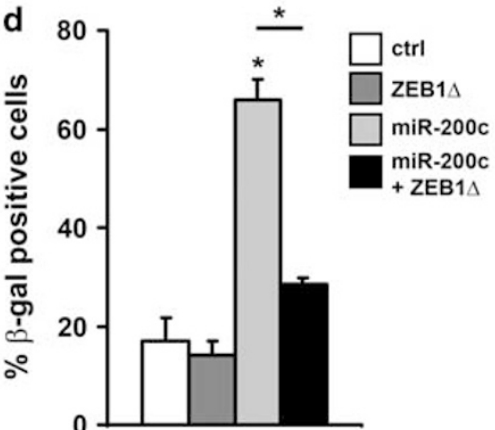

Figure 9 ZEB1 downmodulation is required for miR-200-c-mediated induction of growth arrest apoptosis and senescence. HUVEC were co-infected with lentiviruses encoding miR-200c and ZEB1 $\Delta$ for $2 \mathrm{~h}$. Single infection either of miR-200c or ZEB1 $\Delta$ was performed together with ZEB1 $\Delta$ backbone vector (vec) or miR-scramble viruses, respectively. Control cells were co-infected with miR-scramble and vec viruses. After infection cells were allowed to recover in complete fresh medium for additional $72 \mathrm{~h}$, without puromycin selection and then plated. (a) Representative western blot demonstrating the expression level of ZEB1 in cells co-infected with miR-200c and ZEB1 $\Delta$ miR$200 \mathrm{c}$ forced expression decreased ZEB1, but this effect was largely inhibited in cells expressing ZEB1 $\Delta$. This experiment was performed three times with similar results. Tub, $\alpha$-tubulin. (b) HUVEC co-infected with miR-200c and ZEB1 $\Delta$ showed a higher proliferation rate compared with miR-200c overexpressing cells $(n=5$ at each time point; ${ }^{*} P<0.001 ;{ }^{\#} P<0.05$ ). (c) HUVEC were infected with ZEB1 $\Delta$, miR-200c, miR-200c and ZEB1 $\Delta$ or control viruses. After $72 \mathrm{~h}$, cells were plated and after additional $40 \mathrm{~h}$ apoptosis was measured by fragmentation of cellular DNA. The proapoptotic effect of miR-200c was abolished by the expression of ZEB1 $\Delta$ ( $n=3$; $\left.{ }^{*} P<0.05\right)$. (d) HUVEC were infected with ZEB1 $\Delta$, miR-200c, miR-200c and ZEB1 $\Delta$ or control viruses. After $72 \mathrm{~h}$, cells were seeded and after $8 \mathrm{~h}$ were fixed and stained for SA- $\beta$-gal. Cells co-infected with miR-200c and ZEB1 $\Delta$ showed a decrease of the $\%$ of SA- $\beta$-gal-positive cells compared with miR-200c- infected cells $\left(n=3 ;{ }^{\star} P<0.001\right)$

$\mathrm{H}_{2} \mathrm{O}_{2}$-mediated miR-200c induction. To this end, we infected HUVEC either with a retrovirus encoding a p53-specific shRNA or a control virus (see Supplementary Figure S5A for p53 expression). Interestingly, p53 knockdown markedly inhibited miR-200c upregulation on $16 \mathrm{~h} \mathrm{H}_{2} \mathrm{O}_{2}$ exposure (Figure 10e). We then established whether p53 overexpression induced miR-200c. HUVEC infected either with an adenovirus encoding p53 or a control virus (see Supplementary Figure S5B for p53 expression) showed that, p53 forced expression markedly enhanced miR-200c level (Figure 10f).

Oxidative stress induced by ischemia modulates miR200 gene family in mouse skeletal muscle. These experiments were aimed at establishing whether ROS formation induced by acute hindlimb ischemia modulates miR-200 gene family expression in skeletal muscle, in vivo.

In $p 66^{\text {ShcA }}$ wt mice, acute hindlimb ischemia enhanced $\mathrm{miR}-200 \mathrm{c}$ and $-200 \mathrm{~b}$ expression in adductor muscle samples; miR-200c and $-200 \mathrm{~b}$ achieved their peak expression $14-48 \mathrm{~h}$ after surgery and progressively decreased thereafter. miR141 expression in adductor muscles was not significantly modulated following acute ischemia (Figure 11a); however, a $3.12 \pm 0.63$-fold increase in miR-141 expression was found in tibialis anterior muscles 2 days after femoral artery dissection $(N=4 ; P<0.01$ at 2 days $)$.
To establish whether miR-200c and -200b upregulation following acute hindlimb ischemia was due to ROS formation, we performed the same experiments in $\mathrm{p} 66^{\text {ShcA-I- }}$ mice. ${ }^{2,3}$ Interestingly, the increase of miR-200c and miR-200b expression following acute hindlimb ischemia in adductor muscles, was markedly attenuated in $\mathrm{p} 66^{\text {ShcA-I- }}$ compared with $w t$ mice (Figures $11 \mathrm{~b}$ and $\mathrm{c}$ ).

\section{Discussion}

Oxidative stress has a major role in many pathological conditions ${ }^{16-18}$ and the molecular mechanisms that control the cell response to ROS have been extensively studied. However, the oxidative stress-effect on miRNAs expression in EC has not been investigated, and little is known on the effect of ROS-modulated miRNAs on cell function. ${ }^{19,20}$

From our profiling, applying a stringent cutoff, we found two miRNAs modulated: miR-200c increased but miR-1 decreased. As miR-1 is cardiac and skeletal muscle-specific the $\mathrm{H}_{2} \mathrm{O}_{2}$ effect on miR-1 was confirmed in $\mathrm{C} 2 \mathrm{C} 12$ myoblasts. This result is in contrast with two previous studies in myocardial cells showing an upregulation of miR-1 on $\mathrm{H}_{2} \mathrm{O}_{2}$ exposure. ${ }^{21,22}$ Interestingly, miR-1 is known to promote myogenic differentiation ${ }^{23}$ and our finding on miR-1 

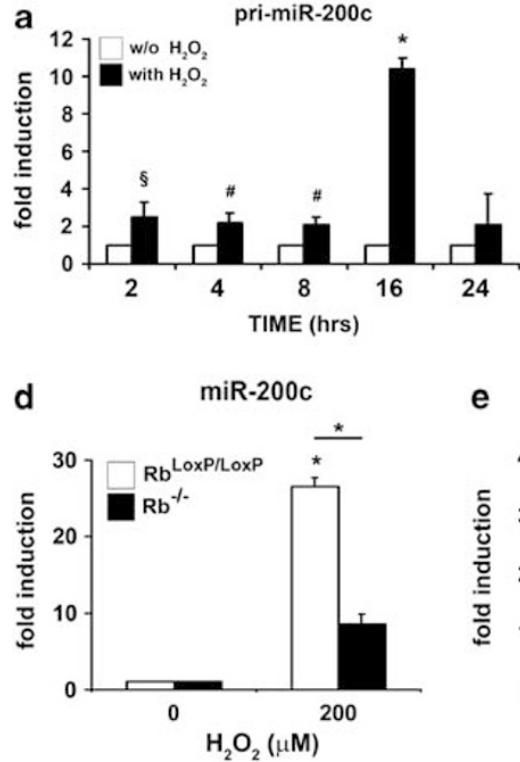

b
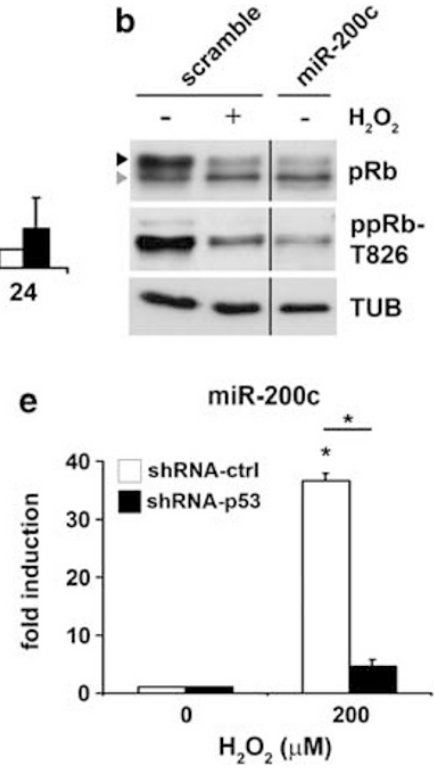

C

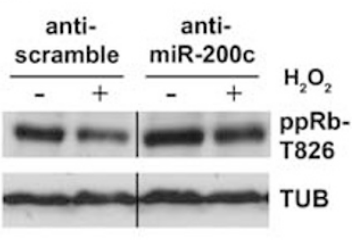

f

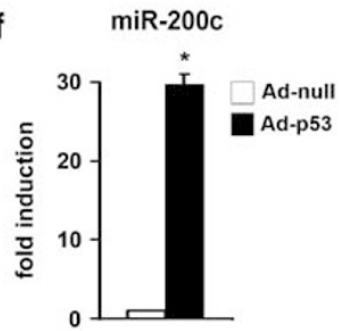

Figure 10 Mechanism of induction of miR-200c by $\mathrm{H}_{2} \mathrm{O}_{2}$. (a) HUVEC were exposed to $200 \mu \mathrm{M} \mathrm{H}_{2} \mathrm{O}_{2}$ for 2-24h; pri-miR-200c level is expressed as fold-induction versus untreated cells, at each time point. $\mathrm{H}_{2} \mathrm{O}_{2}$ enhanced pri-miR-200c and peak expression was achieved after $16 \mathrm{~h}$ exposure to oxidative stress $(n=3$ at each time point; ${ }^{*} P<0.001 ;{ }^{\#} P<0.01 ;{ }^{\S} P<0.05$ ). (b) HUVEC were infected either with a virus encoding miR-200c or with control virus. After selection, cells were plated at the same confluence and treated or not with $200 \mu \mathrm{M} \mathrm{H}_{2} \mathrm{O}_{2}$ for additional $16 \mathrm{~h}$, and then collected. Immunoblots were performed using a pan-pRb antibody or a phospho-pRb antibody. A representative western blot shows that miR-200c induced pRb dephosphorylation comparable to that induced by $\mathrm{H}_{2} \mathrm{O}_{2}$. Gray arrowheads indicate the hypophosphorylated form of pRb; black arrowheads indicate the hyperphosphorylated form. The experiment was performed three times with similar results. Tub indicates $\alpha$-tubulin. (c) HUVEC were transfected either with scramble (anti-scr) or anti-miR-200c (anti-miR-200c) LNA-oligonucleotides. After $16 \mathrm{~h}$, cells were incubated with fresh medium for $8 \mathrm{~h}$ and then $200 \mu \mathrm{M} \mathrm{H}_{2} \mathrm{O}_{2}$ was added to the cells for additional $16 \mathrm{~h}$. A representative western blot using a phospho-pRb antibody shows that after $\mathrm{H}_{2} \mathrm{O}_{2}$ treatment pRb dephosphorylation was lower in anti-200c tranfected cells compared with control cells. (d) pRb ${ }^{\text {loxPlloxP }}$ MEFs infected with the empty vector and with the adenovirus expressing the Cre recombinase were treated with $200 \mu \mathrm{M} \mathrm{H}_{2} \mathrm{O}_{2}$ for $16 \mathrm{~h}$. miR-200c upregulation was higher in pRb ${ }^{\text {loxPlloxP }}$ MEFs compared with $R b^{-l-} \mathrm{MEFs}\left(n=3 ;{ }^{*} P<0.01\right)$. (e) HUVEC were infected either with the control (shRNA-ctrl) or the p53 (shRNA-p53) interfering retroviruses. After selection, cells were treated with $200 \mu \mathrm{M} \mathrm{H} \mathrm{H}_{2} \mathrm{O}_{2}$ for $16 \mathrm{~h}$. p53 knockdown markedly inhibited miR-200c upregulation on $\mathrm{H}_{2} \mathrm{O}_{2}$ treatment $\left(n=3\right.$; $\left.{ }^{*} P<0.001\right)$. (f) HUVEC infected either with control virus (Ad-null) or an adenovirus encoding p53 (Ad-p53) (MOI:50) were collected $48 \mathrm{~h}$ after infection. miR-200c expression was strongly induced on p53 overexpression $\left(n=3 ;{ }^{*} P<0.001\right)$

downmodulation by $\mathrm{H}_{2} \mathrm{O}_{2}$ is in agreement with ROS ability to inhibit myogenic differentiation. ${ }^{3}$

miR-200 family has been extensively studied in the epithelial-to-mesenchimal transition (EMT) of cancer cells; ${ }^{14}$ in EMT miR-200 family downmodulation enhances cancer aggressiveness and metastases, whereas reintroduction of miR-200 family miRNAs in some tumors inhibits their growth. ${ }^{14}$ As ROS inhibit cell proliferation, ${ }^{7,8,24}$ we wanted to establish whether some effects of oxidative stress on cell function could be due to miR-200c upregulation.

In keeping with previous studies from our ${ }^{7,8,24}$ and other laboratories, ${ }^{25,26} \mathrm{H}_{2} \mathrm{O}_{2}$ concentrations used in this paper are within the submillimolar range, and induce negligible EC death in vitro. Therefore the red/ox imbalance achieved is likely close to what is expected to occur in many pathophysiological conditions, for example, reperfusion injury, when oxidative stress induces extensive cell death and organ failure.

We found that $\mathrm{H}_{2} \mathrm{O}_{2}$ had a dose-dependent effect to enhance miR-200c, both in HUVEC and in C2C12 muscle cells. The effect of $\mathrm{H}_{2} \mathrm{O}_{2}$ on the other miR-200 gene family members in HUVEC showed that miR-141, which clusters with miR-200c exhibited a response similar to miR-200c, whereas the other three clustered miRNAs, that is, miR-200a, $\mathrm{miR}-200 \mathrm{~b}$ and miR-429, were all induced, but to a lower level.

Furthermore, miR-200c induction was not limited to $\mathrm{H}_{2} \mathrm{O}_{2}$ because red/ox imbalance obtained by BCNU achieved qualitatively similar effects. These oxidative stress effects on miR-200 family expression were reproduced in vivo, in a mouse model of hindlimb ischemia. We found that miR-200c, miR-200b and miR-141 increased in ischemic skeletal muscles and the increase in miR-200c and miR-200b was markedly attenuated in p66 $\mathrm{ShcA}-1-^{\mathrm{S}}$ mice, confirming the causal role of oxidative stress in the modulation of these miRNAs in vivo.

miR-200c overexpression in HUVEC inhibited cell growth, induced apoptosis and senescence; notably, all these phenomena are caused by oxidative stress as well; ${ }^{1,7,8}$ whereas miR-200c inhibition partially rescued $\mathrm{H}_{2} \mathrm{O}_{2}$-induced effects. It is noteworthy that anti-miR-200c rescue of oxidative stress effects was incomplete, probably because other miR200 family miRNAs may vicariate its functional role. Further, miR-200c effects on cell growth and apoptosis were lowered by transfection procedure used to deliver anti-miR-200c, which is, per se, toxic to HUVEC, inducing partial inhibition of cell growth and apoptosis. ${ }^{8}$

To elucidate the molecular mechanisms of miR-200cmediated effects in EC, we focused on miR-200 family targets ZEB1 and ZEB2 ${ }^{14}{ }^{1}$ It was found that both ZEB1 protein and mRNA were downmodulated by $\mathrm{H}_{2} \mathrm{O}_{2}$ and by miR-200c overexpression. In contrast, ZEB2 protein was undetectable in HUVEC, its mRNA was only slightly downmodulated by $\mathrm{H}_{2} \mathrm{O}_{2}$ and did not vary on miR-200c overexpression. 
a

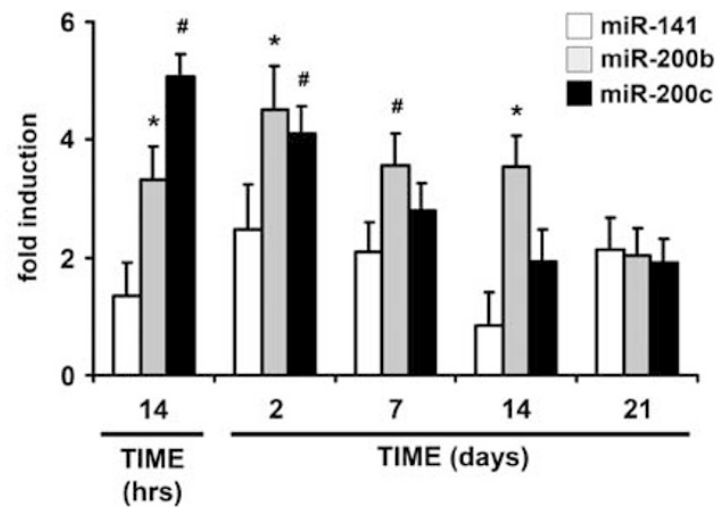

b

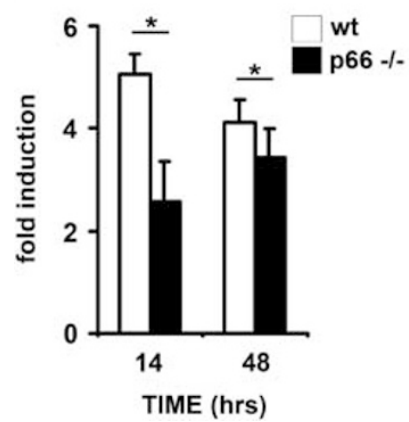

C

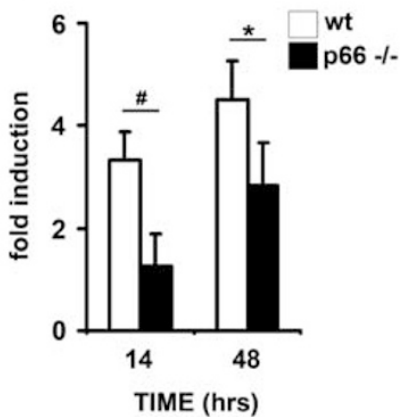

Figure 11 Oxidative stress induced by ischemia modulates miR-200 gene family in mouse skeletal muscles. Acute hindlimb ischemia was induced in $129 \mathrm{~Sv}$ Ev $p 66^{\text {ShcA }}$ wt and $\mathrm{p} 66^{\text {ShcA }-1-}$ mice; adductor muscles were collected at the indicated times. (a) Time course of miR-141, $-200 \mathrm{~b}$ and $-200 \mathrm{c}$ modulation in $\mathrm{p} 66^{\text {ShcA }}$ wt adductor muscles. Acute hindlimb ischemia enhanced miR-200c and $-200 \mathrm{~b}$ expression. Bar graphs represent average fold changes versus sham controls ( $n=4$ at each time point; ${ }^{*} P<0.01$; ${ }^{\#} P<0.05$ ). (b and c) miR-200c and miR-200b levels in $\mathrm{p} 66^{\text {ShcA }}$ wt and p $66^{\text {ShcA }-1-}$ adductor muscles at the indicated time points. miR-200c and miR-200b increase after acute hindlimb ischemia was markedly attenuated in $\mathrm{p} 66^{\mathrm{ShcA}-1-}$ mice in comparison to wt mice. Bar graphs represent average fold changes versus sham controls $(n=4$ at each time point. (b) ${ }^{\star} P<0.05$; (c) ${ }^{*} P<0.001$ and ${ }^{\#} P<0.01$ )

Interestingly, ZEB1 knockdown had effects similar to those caused by miR-200c overexpression and by oxidative stress and we demonstrate a direct implication of ZEB1 downmodulation in the establishment of miR-200c-mediated effects. In fact, expression of a ZEB1 allele that is not targeted by miR-200c reverted miR-200c-induced phenotype, enhancing cell growth and inhibiting apoptosis and senesce.

We cannot rule out that other miR-200 family targets ${ }^{14}$ may have a role in the induction of apoptosis and senescence following oxidative stress, for example, it has been recently shown that the apoptosis-inhibitor FAP1 is a direct target of miR-200c. ${ }^{27}$

Our results are in agreement with other studies on ZEB1. ZEB1 transcription is, in fact, controlled by the $\mathrm{pRb}$ family/E2F cell cycle pathway ${ }^{15}$ and ZEB1 inhibition represses glioblastoma cell proliferation in vitro. ${ }^{28}$ Further, in cortical neurons ZEB1 protein is induced by ischemia and activates a prosurvival response involving p73 proteins. ${ }^{29}$ Finally, the induction of senescence by ZEB1 downmodulation is in agreement with a study, which has shown that Zeb1 mutant
MEFs undergo premature replicative senescence through a mechanism involving the upregulation of p21 expression, and not the INK4a locus. ${ }^{30}$ The authors demonstrated that ZEB1 binds to p21 promoter, inhibiting its expression. In agreement with that study we found that, in ZEB1 knocked-down and in miR-200c overexpressing HUVEC, p21 was upregulated, whereas $p 16 I N K 4 A$ did not increase.

Recently, a report has examined the effect of $\mathrm{H}_{2} \mathrm{O}_{2}$ on miRNAs expression in human fibroblasts and found that miRNAs other than miR-200 family members were induced by oxidative stress. ${ }^{31}$ To elucidate the discrepancy between that study and the present work, we duplicated those experimental conditions. In keeping with Simone et al., ${ }^{31} 25 \mu \mathrm{M} \mathrm{H}_{2} \mathrm{O}_{2}$ failed to induce miR-200c; in contrast, as reported in the present work, $200 \mu \mathrm{M} \mathrm{H}_{2} \mathrm{O}_{2}$ enhanced miR-200c expression level also in human fibroblasts, both at 1 and $16 \mathrm{~h}$ (Supplementary Figure S1).

In keeping with our findings, a recent report has shown that miR-200c is upregulated by chronic oxidative stress-induced senescence in human fibroblasts and in human trabecular meshwork cells. $^{32}$

Finally, we focused on the mechanism of miR-200c induction by $\mathrm{H}_{2} \mathrm{O}_{2}$. We found that, miR-200c was regulated by oxidative stress at the transcriptional level, as pri-miR200c-141 and miR-200c and miR-141 common promoters were upregulated by $\mathrm{H}_{2} \mathrm{O}_{2}$. Interestingly, the kinetic of modulation of the pri-miR-200c-141 resembles the kinetic of modulation of the mature species. Furthermore, we confirmed the presence of the inhibitory loop between ZEB1 and miR200 family. The mutated miR-200c and miR-141 promoter, that lacks the two conserved ZEB1-binding sites, was basally upregulated compared with wt promoter and $\mathrm{H}_{2} \mathrm{O}_{2}$ failed to significantly increase it further, confirming the importance of ZEB1 in miR-200c-transcriptional induction. Moreover, ZEB1 depletion via RNAi in HUVEC induced an upregulation of all family members.

As ZEB1 transcription is modulated the $\mathrm{pRb} / \mathrm{E} 2 \mathrm{~F}$ pathway, we verified the possibility of a reinforcement of ZEB1/miR200 c inhibitory loop ${ }^{15}$ by $\mathrm{pRb}$. In keeping with miR-200c role in the establishment of growth arrest, we found that miR-200c overexpression induced $\mathrm{pRb}$ dephosphorylation and that $\mathrm{H}_{2} \mathrm{O}_{2}$-dependent $\mathrm{pRb}$ dephosphorylation was attenuated by miR-200c inhibition. Furthermore, $\mathrm{H}_{2} \mathrm{O}_{2}$-dependent miR200c upregulation was lower in $\mathrm{Rb}^{-/-}$MEFs than in MEF $R b^{\text {LoxP/LoxP }}$, implicating $\mathrm{pRb}$ in the mechanism of miR-200c upregulation by oxidative stress. We did not establish whether p107 or p130 vicariated pRb function in $R b^{-1-}$ MEFs, nevertheless, the final effect was the attenuation of miR200c upregulation.

The results of the present work and of previous studies indicate that in $\mathrm{EC}, \mathrm{H}_{2} \mathrm{O}_{2}$ causes $\mathrm{pRb}$ dephosphorylation by different mechanisms: PP2A activity, p53 and p21 increase, and also by a miR-200c-dependent mechanism involving a ZEB1-mediated upregulation of p21. As a consequence, $\mathrm{H}_{2} \mathrm{O}_{2}$-dependent $\mathrm{pRb}$ dephosphorylation inhibits E2F activity causing the downmodulation of ZEB1 mRNA, contributing to ZEB1/miR-200 double feedback loop reinforcement (Supplementary Figure S6).

We also found that the oxidative stress-induced protein p53 was involved in $\mathrm{H}_{2} \mathrm{O}_{2}$-mediated miR-200c upregulation. p53 
knockdown, in fact, markedly inhibited $\mathrm{H}_{2} \mathrm{O}_{2}$-dependent miR-200c upregulation, and p53 overexpression induced miR-200c expression in EC, in keeping with a recent paper indicating a role of p53 in EMT, as p53 it is involved in miR-200c transcription. ${ }^{33}$ Therefore, $\mathrm{H}_{2} \mathrm{O}_{2}$-mediated p53 increase and $\mathrm{pRb}$ de-phosphorylation are both involved in miR-200c upregulation, reinforcing ZEB1/miR-200-feedback loop (Supplementary Figure S6).

In summary, the present work shows a key role of miR-200c in the response of non-transformed cells to ROS and suggests that miR-200 family inhibition may represent a therapeutic target to prevent the negative effects of oxidative stress on cell function and survival.

\section{Materials and Methods}

Cell cultures, transfections and plasmids. Cells were grown at $37^{\circ} \mathrm{C}$ in a humidified atmosphere of $5 \% \mathrm{CO}_{2}, 95 \%$ air. Human Umbilical Vein Endothelial cells (HUVEC; Clonetics, Walkersville, MD, USA) were maintained in EGM-2 (Cambrex, East Rutherford, NJ, USA). C2C12 myoblasts were cultured in Dulbeccomodified Eagle medium (DMEM) supplemented with 20\% fetal bovine serum (growth medium). Myoblast terminal differentiation was induced by shifting cells to DMEM containing $2 \%$ equine serum (differentiation medium).

Primary normal human fibroblasts (kind gift from Dr. Zambruno, Istituto Dermopatico dell'Immacolata, Rome, Italy) were grown in DMEM supplemented with $10 \%$ fetal bovine serum. The cell culture was prepared as previously described. ${ }^{34}$ MEFs with conditional $R b$ alleles ( $R b^{\text {LoxP/LoxP }}$ MEFs) infected with the empty vector J-pCA13 or with adenovirus expressing the Cre recombinase (AdCre) to generate MEFs devoid of $\mathrm{pRb}\left(R b^{-1-} \mathrm{MEFs}\right.$ ), were kindly provided by $\mathrm{Dr}$. Marco Crescenzi (Istituto Superiore di Sanità, Rome, Italy). The cell culture was prepared as previously described. ${ }^{35}$ MEFs were grown in DMEM supplemented with $10 \%$ fetal bovine serum, $100 \mathrm{U} / \mathrm{ml}$ penicillin and $0.1 \mathrm{mg} / \mathrm{ml}$ streptomycin (Euroclone, Paignton, Devon, UK).

Drug treatments. Cells were treated with the following drugs. $\mathrm{H}_{2} \mathrm{O}_{2}(30 \% \mathrm{wt} / \mathrm{wt}$ solution; Sigma, St. Louis, MO, USA) was administered to the cells as a $100 \mathrm{mM}$ solution in phosphate-buffered saline (PBS); 1,2-bis (2-aminophenoxy). $N$-acetyl-Lcysteine (Sigma) and 1,3-bis(2 chloroethyl)-1-nitrosourea (Sigma) were dissolved in water.

Western blotting. Cells were lysed in a buffer containing $100 \mathrm{mM}$ Tris (pH 6.8), $20 \%$ glycerol, $4 \%$ SDS. Protein amounts were determined by BCA protein assay kit (Pierce, Rockford, IL, USA). Then DTT (200 mM) was added and lysates were boiled for $5 \mathrm{~min}$. Proteins were separated in SDS polyacrylamide gels and transferred to nitrocellulose by standard procedures. The following antibodies were used to detect the proteins of interest: anti-ZEB1 (H-102; Santa Cruz Biotechnology, Santa Cruz, CA, USA); anti-ZEB2 (H260; Santa Cruz Biotechnology); anti- $\alpha$-tubulin (Ab-1; Oncogene Research Products, La Jolla, CA, USA); anti-p21 (C19-Santa Cruz Biotechnology); anti-pRb (G3-245; Pharmingen, San Diego, CA, USA); antiphospho-pRb-threonine 826 (44-576; Biosource International, Camarillo, CA, USA), anti-p53 (D01- Santa Cruz Biotechnology); anti-actin (AC40, Sigma-Aldrich, St. Louis, MO, USA). Expression levels were evaluated by densitometric analysis using a GS-710 scanner (Bio-Rad, Hercules, CA , USA) and Quantity One software (Bio-Rad). Protein expression was normalized for $\alpha$-tubulin protein levels.

Expression plasmids generation. To overexpress miR-200c, the premiR-200c sequence, including $35 \mathrm{nt}$ of flanking sequences, was cloned between $\mathrm{EcoRI}$ and Agel restriction sites in plKo.1 vector purchased from Sigma.

The pre-miR-200c oligonucleotides sequences used were: forward: 5 '-CCGGG CTGCCTGACCCAAGGTGGGCGGGCTGGGCGGGGGCCCTCGTCTTACCCAGC AGTGTTTGGGTGCGGTTGGGAGTCTCTAATACTGCCGGGTAATGATGGAGGCCC CTGTCCCTGTGTCAGCAACATCCATCGCCTCATTITTG-3'; reverse: 5'-AATTCAAA AATGAGGCGATGGATGTTGCTGACACAGGGACAGGGGCCTCCATCATTACCCGG CAGTATTAGAGACTCCCAACCGCACCCAAACACTGCTGGGTAAGACGAGGGCCC CCGCCCAGCCCGCCCACCTTGGGTCAGGCAGC-3'. The construct was checked by DNA sequencing.
A ZEB1 allele that cannot be targeted by miR-200 family miRNAs (ZEB1 $\Delta$ ) was engineered. ZEB1 CDNA was excised from pCl-Neo-ZEB1 ${ }^{36}$ using Xhol and Xbal and cloned between Sall and Nhel restriction sites in pRRLsin.PPT.CMV. MCS.MM.Wpre using standard procedures. Thus, the last $2552 \mathrm{bp}$ of ZEB1 cDNA (NM_030751.5), encompassing miR-200 family members binding sites, were deleted.

Lentiviral infection. Lentiviral supernatants were produced using standard procedures. ${ }^{37}$ Briefly, HUVEC were infected for $2 \mathrm{~h}$ with lentiviral supernatants and then were allowed to recover in complete fresh medium for additional $24 \mathrm{~h}$. Afterwards, puromycin-containing medium $(0.5 \mu \mathrm{g} / \mathrm{ml}$, Sigma) was added to the cells.

MISSION shRNA lentiviral control and ZEB1-specific constructs were purchased from Sigma.

ZEB1 shRNA sequences are: shRNAZEB1: 5'-CCGGGCTGTTGTTCTGCCAA CAGTTCTCGAGAACTGTTGGCAGAACAACAGCTITT-3'; shRNAZEB1-a: 5'-CCG GGCTGCCAATAAGCAAACGATTCTCGAGAATCGTTTGCTTATTGGCAGCTITा-3'; shRNAZEB1-b: 5'-CCGGCCTCTCTGAAAGAACACATTACTCGAGTAATGTGTTCTTा CAGAGAGGTTIT-3'; shRNAZEB1-C: 5'-CCGGCGGCGCAATAACGTTACAAATCT CGAGATTTGTAACGTTATTGCGCCGTITI-3'.

miRNA overexpression. HUVEC stably expressing miR-200c or miR-control were generated by lentiviral infection using the pre-miR-200c lentiviral supernatants (see Methods above). HUVEC infected with miR-200c lentivirus showed an expression of miR-200c of more than 5000-fold compared with control.

HUVEC coexpressing miR-200c and ZEB1 $\Delta$ were produced by co-infection of cells with both lentiviral supernatants for $2 \mathrm{~h}$. Control cells were co-infected with miR-scramble sequence and ZEB1 $\Delta$ backbone vector (pRRLsin.PPT.CMV. MCS.MM.Wpre) supernatants. Single infections with miR-200c or ZEB1 $\Delta$ were performed together with pRRLsin.PPT.CMV.MCS.MM or miR-scramble viruses, respectively, for $2 \mathrm{~h}$. Afterwards cells were allowed to recover in complete fresh medium for additional $72 \mathrm{~h}$, without puromycin selection. Overexpression of ZEB1 and of miR-200c was confirmed by western blot and qPCR, respectively.

Retroviral infection. Phoenix-ampho cells (American Type Culture Collection) were transfected with pSUPER or pSUPER-shRNA-p53 (a kind gift of Dr. Carlo Gaetano and Dr. Stefania Mattiussi, Istituto Dermopatico dell'Imacolata, Rome, Italy). The medium containing the emerging retrovirus was collected 48 and $72 \mathrm{~h}$ after transfection. HUVEC were then infected and selected with puromycincontaining medium (Sigma; $0.5 \mu \mathrm{g} / \mathrm{ml}$ ).

Adenoviral infection. Adenovirus infection was carried out as previously described. ${ }^{7}$ HUVEC were infected with 50 plaque-forming units per cell with Ad-null and Ad-p53 and cultured for additional $48 \mathrm{~h}$ and then collected.

Anti-miRNAs. Locked Nucleic Acid oligonucleotides against miR-200c or a control sequence bgv(Exiqon) were transfected by siRNA Transfection Reagent (Santa Cruz Biotechnology) in $40 \%$ confluent HUVEC $\left(5000 / \mathrm{cm}^{2}\right)$ at the final concentration of $40 \mathrm{nM}$. After $16 \mathrm{~h}$, cells were incubated with fresh medium for $8 \mathrm{~h}$ and then $200 \mu \mathrm{M} \mathrm{H}_{2} \mathrm{O}_{2}$ was added to the cells for additional $40 \mathrm{~h}$. The expression level of miR-200c was evaluated by qRT-PCR in HUVEC transfected with anti-miR$200 \mathrm{c}$ and compared with control sequence transfected cells. miR-200c expression level was of $68 \pm 0.08 \%$ of control, $P<0.05$.

Flow cytometry. HUVEC were incubated for 30 min with $20 \mu \mathrm{M}$ bromodeoxyuridine (Sigma) and then fixed with $70 \%$ ethanol. Cell cycle analysis was performed by combined BrdU and propidium iodide staining using a Becton Dickinson flow cytometer (Becton Dickinson, Franklin Lakes, NJ, USA). Cell Quest software was used to determine the percentage of BrdU-positive cells.

Apoptosis assay. Apoptosis was assessed by measuring the amount of nucleosomes generated during the apoptotic fragmentation of cellular DNA by Cell Death Detection Elisa (Roche, Basel, Switzerland) according to manufacturer's instructions.

Senescence-associated $\beta$-galactosidase staining. At day 4 after selection with puromycin, HUVEC infected with a lentiviral vector expressing premiR-200c or scramble control, were fixed and stained using a Senescent Cells Staining Kit (Sigma-Aldrich) according to manufacturer's instructions. Briefly, $8 \mathrm{~h}$ after seeding, cells were incubated with $\beta$-galactosidase staining solution for 
additional $24 \mathrm{~h}$ at $37^{\circ} \mathrm{C}$. The reaction was stopped by the addition of PBS, and at least 600 cells were evaluated for $\beta$-galactosidase expression. As a positive control, HUVEC infected with control virus were serum deprived for $64 \mathrm{~h}$.

miRNA and mRNA quantification. Total RNA was extracted using TRIzol (Invitrogen, Paisley, UK) and the TissueLyser system (Qiagen, Valencia, CA, USA). miRNA levels were analyzed using the TaqMan quantitative real-time PCR (qPCR; $1 \mathrm{ng}$ per assay) and quantified with the ABI Prism 7000 SDS (Applied Biosystems, Foster City, CA, USA)

Primers for miR-200c, miR-200a, miR-200b, miR-429, miR-1, miR-147, miR-16 and the reagents for reverse transcriptase and qPCR reactions were all obtained from Applied Biosystems. Pre-miR-200c primers were custom produced from Applied Biosystems (Assay ID:CSXOZQL).

miRNAs expression levels in each sample were normalized to miR-16 expression as, under the experimental conditions of the present study, miR-16 was not modulated by $\mathrm{H}_{2} \mathrm{O}_{2}$ (see Supplementary Table $\mathrm{S} 1$ ). mRNAs levels were analyzed using the SYBR-GREEN qPCR method ( $5 \mathrm{ng}$ per assay, Qiagen) and quantified with ABI Prism 7000 SDS (Applied Biosystems). Relative expression was calculated using the comparative $\mathrm{Ct}$ method $\left(2^{-\Delta \Delta \mathrm{Ct}}\right){ }^{38} \mathrm{mRNA}$ expression was normalized for Beta-2-microglobulin (B2M) levels.

The following primers were used for SYBR-GREEN Real-Time PCR: ZEB1 human: forward: 5'-GGGAGGAGCAGTGAAAGAGA-3'; reverse: 5'-TTTCTTGCCC TTCCTTTCTG-3'. ZEB2 human: forward: $5^{\prime}$-AAGCCAGGGACAGATCAGC-3' reverse: $5^{\prime}$-CCACACTCTGTGCATTTGAACT-3'. B2M human: forward: $5^{\prime}$-TTCT GGCCTGGAGGCTATC-3'; reverse: $5^{\prime}$-TCAGGAAATTTGACTTTCCATTC-3'. Pri-miR-200C-141: forward: 5'-CTTAAAGCCCCTTCGTCTCC-3'; reverse: 5'-AGG GGTGAAGGTCAGAGGTT-3'.

Animal model and surgical procedures. All experimental procedures complied with the Guidelines of the Italian National Institutes of Health and with the Guide for the Care and Use of Laboratory Animals (Institute of Laboratory Animal Resources, National Academy of Sciences, Bethesda, MD, USA) and were approved by the institutional Animal Care and Use Committee. Hindlimb ischemia was induced in 2- to 3-month-old $129 \mathrm{~Sv}$-Ev p $66^{\text {ShcA }}$ wt and p66 $6^{\text {ShcA-1- }}$ male mice with identical genetic background except for the $\mathrm{p} 66^{\text {ShcA }}$ locus. ${ }^{39}$ Mice, 129 Sv-Ev p $66^{\text {ShcA }}$ wt and $-1-$, were anesthetized with an intraperitoneal injection of $2 \%$ Avertin in saline, $25 \mu \mathrm{l} / \mathrm{g}$ body weight (Avertin: $1 \mathrm{~g} / \mathrm{ml}$ 2,2,2-tribromoethyl alcohol in tert-amylalcohol, Sigma). Hindlimb ischemia was induced by dissection of the left femoral artery as previously described. ${ }^{2}$ At various times after surgery adductor and tibialis anterior muscles were collected for RNA extraction.

Luciferase activity assay. The hsa-miR-200c promoter luciferase plasmid and the hsa-miR-200c promoter luciferase plasmid mutated in two ZEB1-binding sites (Z-boxes) were a kind gift of Dr. Thomas Brabletz (University of Freiburg, Freiburg, Germany). ${ }^{40}$

C2C12 myoblasts were transfected by Fugene6 (Roche), with $1 \mu \mathrm{g}$ of pGL3-hsamiR-200c promoter construct or $1 \mu \mathrm{g}$ of pGL3-hsa-miR-200c promoter Z1/Z2mutated plasmid together with $200 \mathrm{ng}$ of $\mathrm{pRL}$-null renilla luciferase encoding plasmid. Thirty-six hours after transfection $\mathrm{C} 2 \mathrm{C} 12$ were treated with $200 \mu \mathrm{M} \mathrm{H}_{2} \mathrm{O}_{2}$ for additional $24 \mathrm{~h}$. Cellular extracts were tested with Dual Luciferase Assay (Promega, Madison, WI, USA), according to manufacturer's instructions using a synergy HT luminometer (Bio Tek Instruments, Winooski, VT, USA). Values were normalized according to renilla luciferase activity.

Statistical analysis. Variables were analyzed by both Student's $t$-test and one-way ANOVA and a $P \leq 0.05$ was deemed statistically significant. Values are expressed as mean \pm S.E.

\section{Conflict of interest}

The authors declare no conflict of interest.

Acknowledgements. This work has been partly supported by Ministero della Salute (R.C.07-1.13, RF07-56.1, RC4.01, RF07 85.1, RF07 onc 26.1, RFS07).

1. Giorgio M, Trinei M, Migliaccio E, Pelicci PG. Hydrogen peroxide: a metabolic by-product or a common mediator of ageing signals? Nat Rev Mol Cell Biol 2007; 8: 722-728.
2. Zaccagnini G, Martelli F, Fasanaro $P$, Magenta A, Gaetano C, Di Carlo A et al. p66ShcA modulates tissue response to hindlimb ischemia. Circulation 2004; 109: 2917-2923.

3. Zaccagnini G, Martelli F, Magenta A, Cencioni C, Fasanaro P, Nicoletti C et al. p66(ShcA) and oxidative stress modulate myogenic differentiation and skeletal muscle regeneration after hind limb ischemia. J Biol Chem 2007; 282: 31453-31459.

4. Bartel DP. MicroRNAs: target recognition and regulatory functions. Cell 2009; 136: 215-233.

5. Chang TC, Mendell JT. microRNAs in vertebrate physiology and human disease. Annu Rev Genomics Hum Genet 2007; 8: 215-239.

6. Delston RB, Harbour JW. Rb at the interface between cell cycle and apoptotic decisions. Curr Mol Med 2006; 6: 713-718.

7. Cicchillitti L, Fasanaro P, Biglioli P, Capogrossi MC, Martelli F. Oxidative stress induces protein phosphatase $2 \mathrm{~A}$-dependent dephosphorylation of the pocket proteins pRb, p107 and p130. J Biol Chem 2003; 278: 19509-19517.

8. Magenta A, Fasanaro P, Romani S, Di Stefano V, Capogrossi MC, Martelli F. Protein phosphatase $2 \mathrm{~A}$ subunit $\mathrm{PR} 70$ interacts with $\mathrm{pRb}$ and mediates its dephosphorylation. $\mathrm{Mo}$ Cell Biol 2008; 28: 873-882.

9. Purdom S, Chen QM. p66(Shc): at the crossroad of oxidative stress and the genetics of aging. Trends Mol Med 2003; 9: 206-210.

10. Giorgio M, Migliaccio E, Orsini F, Paolucci D, Moroni M, Contursi $\mathrm{C}$ et al. Electron transfer between cytochrome $c$ and p66Shc generates reactive oxygen species that trigger mitochondrial apoptosis. Cell 2005; 122: 221-233.

11. Frischer $\mathrm{H}, \mathrm{Ahmad} \mathrm{T}$. Severe generalized glutathione reductase deficiency after antitumor chemotherapy with BCNU" [1,3-bis(chloroethyl)-1-nitrosourea]. J Lab Clin Med 1977; 89 1080-1091.

12. Noda T, Iwakiri R, Fujimoto $\mathrm{K}, \mathrm{Aw}$ TY. Induction of mild intracellular redox imbalance inhibits proliferation of $\mathrm{CaCo}-2$ cells. FASEB J 2001; 15: 2131-2139.

13. Macip S, Igarashi M, Fang L, Chen A, Pan ZQ, Lee SW et al. Inhibition of p21-mediated ROS accumulation can rescue p21-induced senescence. EMBO J 2002; 21: 2180-2188.

14. Brabletz S, Brabletz T. The ZEB/miR-200 feedback loop - a motor of cellular plasticity in development and cancer? EMBO Rep 2010; 11: 670-677.

15. Liu Y, Costantino ME, Montoya-Durango D, Higashi Y, Darling DS, Dean DC. The zinc finger transcription factor ZFHX1A is linked to cell proliferation by Rb-E2F1. Biochem $J$ 2007; 408: 79-85.

16. Griendling KK, FitzGerald GA. Oxidative stress and cardiovascular injury: Part II: animal and human studies. Circulation 2003; 108: 2034-2040.

17. Griendling KK, FitzGerald GA. Oxidative stress and cardiovascular injury: Part I: basic mechanisms and in vivo monitoring of ROS. Circulation 2003; 108: 1912-1916.

18. Giustarini D, Dalle-Donne I, Tsikas D, Rossi R. Oxidative stress and human diseases: origin, link, measurement, mechanisms, and biomarkers. Crit Rev Clin Lab Sci 2009; 46 241-281.

19. Lin Y, Liu X, Cheng Y, Yang J, Huo Y, Zhang C. Involvement of microRNAs in hydrogen peroxide-mediated gene regulation and cellular injury response in vascular smooth muscle cells. J Biol Chem 2009; 284: 7903-7913.

20. Wang Z, Liu Y, Han N, Chen X, Yu W, Zhang W et al. Profiles of oxidative stress-related microRNA and mRNA expression in auditory cells. Brain Res 2010; 1346: 14-25.

21. Tang $Y$, Zheng J, Sun $Y$, Wu Z, Liu Z, Huang G. MicroRNA-1 regulates cardiomyocyte apoptosis by targeting Bcl-2. Int Heart J 2009; 50: 377-387.

22. Xu C, Lu Y, Pan Z, Chu W, Luo X, Lin $\mathrm{H}$ et al. The muscle-specific microRNAs miR-1 and miR-133 produce opposing effects on apoptosis by targeting HSP60, HSP70 and caspase9 in cardiomyocytes. J Cell Sci 2007; 120: 3045-3052.

23. Chen JF, Mandel EM, Thomson JM, Wu Q, Callis TE, Hammond SM et al. The role of microRNA-1 and microRNA-133 in skeletal muscle proliferation and differentiation. Nat Genet 2006; 38: 228-233.

24. Fasanaro P, Magenta A, Zaccagnini G, Cicchillitti L, Fucile S, Eusebi F et al. Cyclin D1 degradation enhances endothelial cell survival upon oxidative stress. FASEB J 2006; 20 1242-1244.

25. Valen G, Erl W, Eriksson P, Wuttge D, Paulsson G, Hansson GK. Hydrogen peroxide induces mRNA for tumour necrosis factor alpha in human endothelial cells. Free Radic Res 1999; 31: 503-512.

26. Zadeh MS, Kolb JP, Geromin D, D'Anna R, Boulmerka A, Marconi A et al. Regulation of ICAM-1/CD54 expression on human endothelial cells by hydrogen peroxide involves inducible NO synthase. J Leukoc Biol 2000; 67: 327-334.

27. Schickel R, Park SM, Murmann AE, Peter ME. miR-200c regulates induction of apoptosis through CD95 by targeting FAP-1. Mol Cell 2010; 38: 908-915.

28. Yen G, Croci A, Dowling A, Zhang S, Zoeller RT, Darling DS. Developmental and functional evidence of a role for Zfhep in neural cell development. Brain Res Mol Brain Res 2001; 96 $59-67$.

29. Bui T, Sequeira J, Wen TC, Sola A, Higashi Y, Kondoh H et al. ZEB1 links p63 and p73 in a novel neuronal survival pathway rapidly induced in response to cortical ischemia. PLOS One 2009; 4: e4373.

30. Liu Y, El-Naggar S, Darling DS, Higashi Y, Dean DC. Zeb1 links epithelial-mesenchymal ransition and cellular senescence. Development 2008; 135: 579-588.

31. Simone NL, Soule BP, Ly D, Saleh AD, Savage JE, Degraff $W$ et al. Ionizing radiationinduced oxidative stress alters miRNA expression. PLoS One 2009; 4: e6377.

32. Li G, Luna C, Qiu J, Epstein DL, Gonzalez P. Alterations in microRNA expression in stress-induced cellular senescence. Mech Ageing Dev 2009; 130: 731-741. 
33. Chang CJ, Chao CH, Xia W, Yang JY, Xiong Y, Li CW et al. p53 regulates epithelialmesenchymal transition and stem cell properties through modulating miRNAs. Nat Cell Biol 2011; 13: 317-323.

34. Cianfarani F, Baldini E, Cavalli A, Marchioni E, Lembo L, Teson M et al. TSH receptor and thyroid-specific gene expression in human skin. J Invest Dermatol 2010; 130: 93-101.

35. Camarda G, Siepi F, Pajalunga D, Bernardini C, Rossi R, Montecucco A et al. A pRbindependent mechanism preserves the postmitotic state in terminally differentiated skeletal muscle cells. J Cell Biol 2004; 167: 417-423.

36. Postigo AA, Dean DC. ZEB, a vertebrate homolog of Drosophila Zfh-1, is a negative regulator of muscle differentiation. EMBO J 1997; 16: 3935-3943.
37. Follenzi A, Naldini L. HIV-based vectors. Preparation and use. Methods Mol Med 2002; 69: 259-274.

38. Livak KJ, Schmittgen TD. Analysis of relative gene expression data using real-time quantitative PCR and the 2(-Delta Delta C(T)) Method. Methods 2001; 25: 402-408.

39. Migliaccio E, Giorgio M, Mele S, Pelicci G, Reboldi P, Pandolfi PP et al. The p66shc adaptor protein controls oxidative stress response and life span in mammals. Nature 1999; 402: 309-313.

40. Burk U, Schubert J, Wellner U, Schmalhofer O, Vincan E, Spaderna S et al. A reciprocal repression between ZEB1 and members of the miR-200 family promotes EMT and invasion in cancer cells. EMBO Rep 2008; 9: 582-589.

Supplementary Information accompanies the paper on Cell Death and Differentiation website (http://www.nature.com/cdd) 